EstAg 33 (1998) 487-524

\title{
Estructura de la Regla de San Agustín (IV)
}

\subsection{Los libros 1-9 de las Confessiones 2 y la Regla}

Refiriéndose a las Confessiones, escribe A. de Vogüé: «El monacato ocupa en ellas un lugar a la vez mínimo y central». El sabio benedictino fundamenta su juicio en el hecho de que, sin hablar propiamente en ellas de la propia vida monástica, atestan el rol decisivo que jugó, en su conversión del 386, el descubrimiento de la existencia de Antonio y de otros monjes 3 . De hecho, los estudiosos del monacato agustiniano conceden gran importancia en la génesis del mismo a ese hecho, así como al frustrado intento de vida común en Milán, anterior a la conversión ${ }^{4}$.

Nuestro interés no lo constituye el monacato de san Agustín, sino su Regla y, específicamente, su estructura. Por ello, al acercarnos a C1-9 lo hacemos de forma global 5 , sin limitarnos a aquellos pasajes que hablan de vida monástica u otra asimilada a la monástica. Nuestro intento es mostrar que en esta primera parte de la obra maestra agustiniana se detecta una estructura 6 que bien pudiera ser la que sostiene la Regla.

1. Cf. Estructura de la Regla de san Agustín (I-III), en Estudio Agustiniano 32 (1997) $407-$ 430; 33 (1998) 5-53; 227-270.

2. En adelante, C1-9. En las referencias a libros concretos utilizaremos sólo la $\mathrm{C}$ seguida del número del libro o libros: $\mathrm{C} 1, \mathrm{C} 2, \mathrm{C} 3$, etc.

3. Histoire littéraire, 3,208. «Pero acerca del monacato (las Confesiones) nos informan muy poco. No sabemos si Agustín fue un monje observante, o qué entendía él por observancia. Sólo en el libro XIII y último de la obra se le ocurre interpretar el Génesis en sentido espiritual...» (L. Cilleruelo, El monacato de san Agustín, Valladolid 1966, p. 262). Por otra parte, P. Brown considera que la obra la dirige el Santo a los ascetas católicos para exponerles sus puntos de vista sobre el ascetismo (The Body and Society: Men, Women, and Sexual Renuntiation in Early Christianiny, 1988, p. 388).

4. Conf. 6,14,24. Cf. A. Zumkeller, Das Mönchtum des hl. Augustinus, Würzburg $1968^{2}$, 37-41; A. MANRIQUe, La vida monástica en san Agustín. Enchiridion histórico-doctrinal y Regla, El Escorial 1959, pp. 30-35; L. Cilleruelo, El monacato..., pp. 47-69; J. VeGA, La vocación agustiniana. El proyecto filosófico-monástico-sacerdotal de san Agustín, Valladolid 1987, cap. V y VI, pp. 51-109.

5. En realidad, del libro noveno sólo nos interesará su primer capítulo.

6. No nos ocupamos aquí de la estructura general de las Confessiones, cuestión que ha sido y sigue siendo muy debatida. La amplia bibliografía al respecto puede verse en cualquier 
Todo conocedor de las Confessiones sabe que la obra consta de tres partes, netamente definidas. La primera la componen los libros del uno al nueve, la segunda el décimo y la tercera los tres siguientes y últimos. Lo lógico hubiera sido, pensará el lector que haya leído nuestro anterior artículo en que comparábamos a nivel de estructura la Regla con C10 7, haber mantenido este mismo orden. Ajustándonos a él, tendríamos que haber antepuesto este apartado al anterior, haber comenzado la comparación con la Regla con C19 y haber seguido con C10. Pero tampoco carece de lógica el orden que, de hecho, estamos siguiendo. Obedece a un triple principio: genético, uno; de certeza, otro; de criterio, otro. Genético porque hemos percibido el paralelismo con la Regla de la primera parte de las Confessiones después de haber estudiado el de la segunda. De certeza, porque, respecto de esta, el paralelismo aparece claro y, respecto de aquella, no nos parecía tanto al comienzo, aunque el grado de certeza ha ido aumentando a medida que avanzaba el estudio. De criterio, porque C10 nos ofrece con nitidez una estructura desde la que podemos juzgar C1-9.

\subsubsection{La estructura de C1-8.}

En su voluminoso comentario a las Confessiones, J. J. O’Donnell admite que los libros 1-8 están organizados sobre la pauta de 1 Jn 2,168. En su opinión, los libros 2-4 refieren la caída, respectivamente, en la concupiscencia de la carne, la de los ojos y la ambición mundana 9 . Los libros 6-8 representan,

introducción general a la obra. A modo de ejemplo, cf. SANT'Agostino, Confessioni. A cura di J. Fontaine, M. Cristiani, J. Guirau, L.F. Pizzolato, M. Simonetti, P. Siniscalco. Traduzione di G. Chiarini. Volume I. Libri I-III. Vicenza 1992, p. CXLV-CXLVI.

7. Cf. Estructura (III), en Estudio Agustiniano 33 (1998) 227-270.

8. Augustine: Confessions. Volume I. Introduction and Text. Oxford 1992, p. XXXV: «But that depiction of the present state of Augustine's soul as a victim of the three temptations of 1 Jn 2:16 must be taken seriously; indeed, taken seriously enough, it opens another line of sight into de organization of the earlier books of the work».

9. «A pattern of conduct can be traced through Bks. 2-4 according to which Augustine sins first according to the concupiscence of the flesh (both the sexual sins of adolescence and the symbolic re-enactment of the fall implied by the incident of the pear tree), next according to the concupiscence of the eyes (described mainly in Bk. 3, where he falls prey to one sort of curiositas in his mania for the spectacula of Carthage and to another in his allegiance to the Manichees), and finally according to the ambitio saeculi (which is most lightly touched on at this stage -see on 4,7,12» (I, XXXV; cf. también II,217). También H. Kusch considera que $1 \mathrm{Jn}$ 2,16 es un elemento importante en la estructura de la primera parte de las Confessiones, pero lo limita a los libros 2-4 en los que quedaría reflejado el homo vetus frente al homo noulus de 
en cambio, el momento de su resurgir moral, según un orden inverso 10.

Estamos de acuerdo con J.J. O'Donnell en la afirmación general de que C1-8 tienen en 1 Jn 2,16 un criterio de organización, pero no podemos seguirle siempre en las propuestas concretas respecto de cada uno de los libros. La continuación del estudio mostrará los puntos de desacuerdo.

Esta parte primera de la obra que nos disponemos a examinar consta de tantos libros como capítulos tiene la Regla. Una coincidencia puramente material. Más significativa es la segunda, que se refiere ya a su estructuración interna. Responde a su contenido mismo dividirla en tres partes, que llamaremos también secciones, para atenernos a la terminología utilizada para los otros textos analizados. La sección A corresponde al libro primero; la $\mathrm{B}$, a los seis libros siguientes, del segundo al séptimo; la C, al libro octavo. Estructura coincidente en lo esencial con lo que hemos establecido para la Regla 11.

Alguien pudiera pensar que estas correspondencias obedecen a criterios arbitrarios, fruto de un afán desmesurado de encontrar paralelismos con la Regla. Nosotros nos limitamos a exponer algunos datos, y luego que el lector juzgue sobre el carácter objetivo de tal división.

Para establecer dichas secciones, no hemos seguido más criterio que el del contenido. $\mathrm{C} 1$ (= sección $\mathrm{A}$ ) señala la meta, destino y objetivo vital y cristiano del hombre Agustín; C2-7 (= sección B) describen su peregrinar errante desde el esquema de las tres concupiscencias 12; C8 (= sección C), por último, refiere cómo Jesucristo pasó a dar sentido concreto a la vida del entonces joven profesor de retórica. A partir de aquí, nos parece claro el paralelismo con los textos examinados de DVR y de $\mathrm{C} 10$ y, por supuesto, con la Regla.

C10-13. C5-6 y C7-9 representarían las etapas que posibilitan el cambio: sometimiento a la autoridad bíblica y renovación y purificación respectivamente (cf. Studien über Augustinus. I. Trinitarisches in Büchern 2-4 und 10-13 der Confessiones, en Festschrift Franz Dornseiff zum 65. Geburtstag, hrsg. von H. Kusch, Leipzig, VEB Bibliographisches Institut 1953, pp. 124-183).

10. «The moral rise of Augustine, that parallels but does not duplicate the ascent of the mind, follows a reverse order: his zeal for his public career fades first at Milan (en nota: esp. the incident of the drunken beggar at 6.6.9), then his adhesion to the spirit of curiosity that had led him to the Manichees, and only last his enslavement to the desires of the flesh (en nota: In the garden scene specifically and Bk. 8 generally). It is that liberation that comes between the Milan and Ostia visions and makes possible the higher vision that comes to at Ostia and in Bks. 10 and following» (I, XXXV-XXXVI). En esto coincide, aunque sólo parcialmente con $\mathrm{H}$. Kusch. Cf. la nota precedente. la Regla.

11. En lo esencial, porque en C1-8 faltan tanto el prólogo como el epílogo, presentes en

12. Hablamos de las tres concupiscencias por simplificar; igualmente podríamos hablar de las tres cupiditates (voluptatis uel excellentiae uel spectaculi) (cf. Estructura (II), en Estudio Agustiniano 33 (1998) p.10, notas 18 y 20). La misma realidad es designada por san Agustín de múltiples maneras (cf. Estructura (I), en Estudio Agustiniano 33 (1997) p. 424, nota 56). 
A continuación trataremos de probar esta afirmación. En cada apartado fijamos primero los datos de C1-8; luego establecemos la comparación con la Regla.

\subsubsection{Sección A (C1)}

Núcleo doctrinal del libro primero de las Confessiones consideramos, sin duda, la célebre frase que aparece ya en el capítulo inicial: «Nos hiciste, Señor, para ti y nuestro corazón está inquieto hasta que descanse en ti» ${ }^{13}$. El hombre está orientado y dinamizado hacia Dios ( ad te) por el deseo de hallar el descanso y la paz en él (requiescat in te). El fundamento último de tal inquietud y deseo no es otro que el hecho de la creación (fecisti).

Inseparable de ese núcleo doctrinal es su aspecto social, señalado en el «nos hiciste» y en el «nuestro corazón» 14. Según el santo, el hecho de que en el evangelio (cf. Mt 22,37-40; Lc 10,27) el Señor ordene junto el amor a Dios el amor al prójimo como a uno mismo, indica al hombre que no puede pretender gozar (frui) de Dios individualmente, desvinculado de los demás ${ }^{15}$.

El conjunto de C1 muestra la presencia ontológica de Dios en el hombre, consecuencia de la creación, y cómo de ella se derivan sus anhelos más profundos y nobles ${ }^{16}$. Pero si el hombre cuenta con los dones de Dios que orientan sus deseos hacia él, cuenta también con la presencia maléfica del pecado que pervierte la dirección de los mismos ${ }^{17}$.

13. «Fecisti nos ad te et inquietum est cor nostrum, donec requiescat in te» (Conf. 1,1,1 CC 27,1). En adelante daremos la referencia interna de las Confesiones con la indicación única de la página de CC 27.

14. Teniendo en cuenta, sobre todo, que inmediatamente el texto vuelve al singular: «da mihi, domine, scire» $(1,1,1: 1)$.

15. Cf. L. VERHEIJEN, La premièr livre du De doctrina christiana d'Augustin. Un traité de «télicologie» biblique, en Traiectina Augustiniana, Paris 1987, pp. 169-187. Según el sabio agustino san Agustín juzga «las cosas» en función de Dios y en función de nuestra situación final, definitiva y común junto a Dios. Se trata de un método de juzgar que caracteriza la espiritualidad del santo (ib.).

16. Cf. 1,20,31:17. Cf. nota 20.

17. Dicha perversión tiene su origen tanto en el pecado de origen (cf. 1,7,11:6) como en la mala semilla sembrada por sus educadores $(1,9,14: 8 \mathrm{ss})$. Pecado como efecto y orgullo como causa que aparecen mencionados ya en el primer párrafo de la obra: «... et homo circumferens testimonium peccati sui et testimonium quia resistis superbis» $(1,1,1: 1)$. Superbia, en su varias formas gramaticales (sustantivo, adjetivo, adverbio o verbo), es un concepto dominante en las Confessiones. En el conjunto de la obra se contabilizan 45 presencias, 30 de ellas en los ocho primeros libros (cf. M. TESTARD, La "superbia" dans les Confessions de saint Augustin, en Homo Spiritalis. Festgabe für Luc Verheijen OSA zu seinem 70. Geburtstag. Hrsg. von C. Mayer unter Mitwirkung von K. H. Chelius, Würzburg 1987, 136-170; esp. 136; 
No creemos que sea forzar los textos ver aquí un paralelismo con la sección A de la Regla. Su núcleo lo constituye el caminar hacia Dios (in deum). El modo de realizar ese camino es asimismo social: en unidad de almas y corazones ${ }^{18}$. Condición de posibilidad es anular las fuerzas que tiran en otra dirección: aquí, el orgullo individualista.

En esquema:

C1: Nos hiciste para ti... hasta que descanse en ti / «nuestro» / el obstáculo del pecado.

Regla: Hacia Dios / unidad de almas y corazones / el obstáculo del orgullo.

\subsubsection{Sección $B(C 2-7)$}

Poco ha señalamos que la sección B (C2-7) describe el peregrinar errante del joven Agustín desde el esquema de las tres concupiscencias. Ahora podemos entrar ya en más detalles. La distribución de los seis libros de que consta esta sección en las diferentes «unidades»-según la terminología que venimos utilizando- sería la siguiente:

C2 y C6: unidad segunda (= concupiscencia de la carne).

C3 y C7: unidad primera (= concupiscencia de los ojos).

C4 y C5: unidad tercera (= ambición mundana).

A cada unidad le corresponden, pues, dos libros, uno de la primera terna (C2-4), y otro de la segunda (C5-7).

Las ternas no son idénticas. En principio cabía esperar que los dos bloques fueran simétricos, aun dentro de una eventual inversión del orden en forma de quiasmo ${ }^{19}$, pero no es el caso. En la primera terna la sucesión es: concupiscencia de la carne (C2), concupiscencia de los ojos (C3) y ambición mundana (C4); en la segunda: ambición mundana (C5), concupiscencia de la

en $n .1$ bibliografía al respecto). El concepto remite siempre a una «perversa» relación, ya sea con Dios, ya con los demás hombres. En su relación con las concupiscencias, hay que tener en cuenta este doble aspecto. En cuanto relación "perversa» con Dios -negativa a someterse a Él- está en el origen de las concupiscencias, siendo estas el castigo merecido por ella; en cuanto relación «perversa» con los demás hombres - afán por dominar, de la forma que sea, sobre quienes son iguales-, se identifica en la práctica con la ambición mundana. Una y otra acepción de hallan en las Confessiones.

18. En ningún modo pretendemos dar idéntico sentido al nostrum de $\mathrm{C} 1$ que a anima una et cor unum de la Regla. Simplemente pretendemos señalar cómo el hombre no va sólo hacia Dios.

19. Es lo que acontece, p. e., en De uera religione entre $39,72-52,101$ de una parte y $53,102-54,106$ de otra. 
carne (C6) y concupiscencia de los ojos (C7). El hecho quizá haya que interpretarlo como simple sujeción a la realidad histórica, esto es, a la situación personal concreta en cada momento. Aunque la historia se encuadre en una determinada estructura, la estructura no avasalla la historia.

Más importante es otro particular. En cada uno de los libros de la primera terna (C2-4) el santo se presenta a sí mismo subyugado por las tres concupiscencias. En C2 de forma general, en $\mathrm{C} 3$ y C4 de forma más específica.

El capítulo inicial de C2 sirve de introducción a toda la sección $\mathrm{B}$ y, a la vez, a este libro. Para entenderlo hay que partir de la conclusión del libro anterior del que es continuación y también explicitación. Allí elencaba los dones de Dios: la memoria, el lenguaje, la amistad, así como el rehuir el dolor, la ignorancia y la abyección; refería también el efecto perturbador del pecado, merced al cual, en vez placer/dulzura, honor/dignidad y verdad había cosechado dolor, error y deshonra ${ }^{20}$. Pecado que consistió precisamente en buscar los valores señalados en las criaturas, en sí mismo y en los demás, no en Dios. Tales son las fealdades pasadas y las corrupciones carnales de su alma que se propone relatar. A ello le mueve el deseo de recomponerse de la dispersión, puesto que, al apartarse de Dios que es la Unidad y disiparse en multitud de cosas, se había disgregado y hecho añicos 21 . Como prueba de esa dispersión aduce el vivo deseo, en el tiempo de su adolescencia, de saciarse de las cosas más bajas, y la osadía de convertirse en una selva de varios y sombríos amores, junto con el ansia de complacerse a sí y complacer a los demás 22. Ahora bien, estas reflexiones traen inmediatamente a la memoria otras de C10. Cuando el santo se dispone a examinar su conciencia respecto de las tres concupiscencias, antes evoca su contraria, la continencia, presentada con términos muy cercanos a los que acabamos de ver: «Por medio de la continencia nos recomponemos y somos devueltos a la Unidad desde la que caímos en la multiplicidad» 23. Y de nuevo, como prueba de la dispersión, los varios amores desgajados del de Dios: «Pues menos te ama el que contigo ama otra

20. «... memoria uigebam, locutione instruebar, amicitia mulcebar, fugieban dolorem, abiectionem, ignorantiam... Hoc enim peccabam quod non in ipso, sed in creaturis eius me atque ceteris uoluptates, sublimitates, ueritates quaerebam, atque ita inruebam in dolores, confusiones, errores» (Conf 1,20,31: 17).

21 . «... et colligens me a dispersione, in qua frustratim discissus sum, dum ab uno te auersus in multa euanui» (Conf. 2,1,1:18).

22. «Exarsi enim aliquando satiari inferis in adulescentia et siluescere ausus sum uariis et umbrosis amoribus... et contabuit species mea et computrui coram oculis tuis placens mihi et placere cupiens oculis hominum» (Conf. 2,1,1:18).

23. «Per continentiam quippe colligimur et redigimur in unum a quo in multa defluximus» (Conf. 10,29,40:176). Es evidente que detrás de estas expresiones están Plotino y 
cosa que no ama por ti» ${ }^{24}$. Como en C10 la mención explícita de la continencia abre a la consideración de las tres concupiscencias, el texto paralelo de $\mathrm{C} 2$ abre también el paso a la consideración de las mismas.

Si C2 habla de las concupiscencias de forma genérica ${ }^{25}$, en los tres primeros capítulos de C3 san Agustín refiere por separado el modo como cada una de ellas se manifestaba en su vida de estudiante en Cartago: la de la carne, en sus devaneos sexuales; la de los ojos, en su afición al teatro; la ambición, en el orgullo que experimentaba por ser el primero en la escuela de retórica ${ }^{26}$. También $\mathrm{C} 4$ refiere idéntica sumisión. Y lo hace por partida doble, esto es, con dos ternas. En el primer capítulo Agustín se presenta como devoto cultivador de las viejas amistades: la vacuidad de la gloria popular, los espectáculos frívolos y las intemperancias de la carne ${ }^{27}$. En el segundo introduce una nueva terna en la que la avaricia ocupa el lugar de la curiosidad 28. Con relación a esta última hay que señalar como dato novedoso el que reco-

Porfirio, pero este aspecto carece de importancia para lo que nos ocupa. Para los textos de ambos filósofos, cf. O’DonNell, Augustine: Confessions, II, 107.

24. «Minus enim te amat qui tecum aliquid amat, quod non proter te amat» (Conf. 10,29,40:176).

25. La terna aparece expresamente más adelante: «Etenim species est pulchris corporibus et auro et argento et omnibus, et in contactu carnis congruentia ualet plurimum ceterisque sensibus est sua cuique accommodata modificatio corporum; habet etiam honor temporalis et imperitandi atque superandi potentia suum decus, unde etiam uindictae auiditas oritur...» $(2,5,10: 22)$.

26. Para la concupiscencia de la carne, cf. 3,1,1:27 («Et ideo non bene ualebat anima mea et ulcerosa proiciebat se foras, miserabiliter scalpi auida contactu sensibilium»); para la de los ojos, cf. 3,2,2-3,5:27-29 («Rapiebant me spectacula theatrica, plena imaginibus miseriarum mearum»; para la ambición mundana, cf. 3,3,6:29 («Habebant et illa studia quae honesta uocantur, ductum suum..., ut excellerem in eis, hoc laudabilior quo fraudulentior. Tanta est caecitas hominum de caecitate etiam gloriantium. Et maior iam eram in schola rhetoris et gaudebam superbe et tumebam typho»). «L'adverbe "superbe"... se trouve confirmé et renforcé par le verbe "tumebam" et le substantif "typho". Nous apprenons par la suite qu'Augustin n'était tête de classe et ne se prévalait de ses succès que dans le domaine intellectuel. Vivant au milieu de chahuteurs, bien loin d'en prendre la tête, comme un meneur, il demeurait calme, a l'écart. Mais ce n'était pas vertu et ce premier de classe orgueilleux avait honte de ne pas exceller aussi dans ces chahuts dont il avait horreur» (M. TESTARD, La "superbia" dans les Confessions, p. 143-144).

27. «... hac popularis gloriam sectantes inanitatem usque ad theatricos plausus et contentiosa carmina et agonem coronarum faenarum et spectaculorum nugas et intemperantiam libidinum» $(4,1,1: 40)$.

28. «Docebam in illis annis artem rhetoricam et uictoriosam loquacitatem uictus cupiditate uendebam... In illis annis habebam non eo quod legitimum uocatur coniugio cognitam, sed quam indagauerat uagus ardor inops prudentiae...; in qua sane experirer... quid distaret inter coniugalis placiti modum... et pactum libidinosi amoris... Recolo tamen, cum mihi thea- 
nozca en cada caso un rayo de luz en medio de su oscuridad ${ }^{29}$, algo que no hace respecto de la primera.

Así, pues, C2, C3 y C4 comienzan todos ellos con la referencia clara a las diversas concupiscencias. Es como el motivo general que domina esta subsección. Pero luego cada uno de los libros se centra sobre la concupiscencia específica ya indicada ${ }^{30}$, aunque sin olvidar del todo las otras.

La situación descrita en esta primera terna se puede comparar a una guerra. En ella Agustín se ha de enfrentar a un auténtico ejército, con tres cuerpos de acción, en orden de batalla. Aunque en un momento determinado el peso de la batalla recaiga sobre uno de ellos en particular, los otros le sirven de apoyo e intervienen en acciones puntuales. Y si en algún caso Agustín sale vencedor frente a un cuerpo, luego cae derribado por otro.

La segunda terna, C5-7, nos presenta un estado de cosas parcialmente diferente. De hecho, ninguno de los tres libros comienza como los anteriores. Pero también cada uno de ellos tiene como motivo estructurante una de las tres concupiscencias. Siguiendo con la imagen militar, parece como si los diferentes cuerpos del ejército ya no proyectaran la guerra en común; siguen en plan de ataque, pero la guerra ya la hacen cada uno por su cuenta, no obstante uniones tácticas pasajeras. Además, la victoria no siempre está de su lado.

Es lo que vamos a ver a continuación. Seguimos el orden de unidades que antes establecimos.

\subsection{Unidad segunda (C2 y C6).}

Aun la lectura más superficial de C2 permite ver que, aparte el prólogo $(, 1,1)$ y el epílogo $(10,18)$, consta de dos partes. En la primera $(2,2-3,8)$ el santo refiere sus pecados relacionados con la sexualidad; en la segunda (4,9$9,17)$ confiesa el robo de las peras, pecado que, en su materialidad al menos, cae dentro del ámbito alimenticio. Tal es la estructura material y simple del

trici carminis certamen inire placuisset, mandasse mihi nescin quem aruspicem, quid ei uellem dare mercedis, ut uincerem, me aulc $11 \ldots$... respondisse...» $(4,2,2-3: 40-41)$.

29. «... uidisti de longiquo fidem meam, quam exibebam in illo magisterio...; sed unam tamen...; nec si corona illa esset inmortaliter aurea, muscam pro uictoria mea necari sinere» $(4,2,2-3: 40-41)$.

30. Estamos de acuerdo con H. Kusch cuando afirma que «Die Bücher 2-4 rücken jeweils ein Glied der Begierdentriade in den Mittelpunkt der Analyse und Betrachtung», pero disentimos de él cuando indica qué concupiscencia predomina en cada libro concreto: «Buch 2 setz den Akzent in der superbia als Loslösung von der Gottgewollten Ordnung; den Birnendiebstahl is Augustins adamitischer Fall, er documentiert die endgültige Hinwendung zur Welt und zum Ich. Buch 3 hat zum Hauptproblem die curiositas, Buch 4 den falsch gerichteten amor» (Studien über Augustinus, p. 147). 
libro ${ }^{31}$. Ahora bien, el de la sexualidad y el alimenticio son dos campos privilegiados para la manifestación de la concupiscencia de la carne 32 .

Como señalamos, en el prólogo el santo hace referencia a la dispersión y multiplicidad en que, alejándose de la Unidad divina, había caído durante el período de su adolescencia. Los ejemplos que aduce de dicha caída apuntan ya a la consideración de la primera concupiscencia, la de la carne. Aunque sea a nivel de imagen, la terminología del «saciarse» y de los «amores sombríos», sobre todo en el contexto de lo que sigue, nos coloca en el ámbito de las dos manifestaciones antes señaladas de la misma: el del alimento y el de la sexualidad 33. En el mismo ámbito nos colocan las consecuencias que, según él, se derivaron de su disgregación: el ver marchitada su hermosura y resultar podrido a los ojos de Dios ${ }^{34}$.

Además, el segundo capítulo de C2 menciona ya explícitamente la concupiscencia de la carne como fuente inmediata de su comportamiento inmoral, consistente en no mantener el modus en su amor 35. Fuente inmediata, porque fuente última es la mortalidad, fruto de la ira de Dios, provocada, a su vez, por el orgullo del hombre 36.

La concupiscencia de la carne, en su manifestación sexual, es evidente en C2 y no es preciso detenerse más en ello. Pero ¿se puede afirmar lo mismo en lo que se refiere al ámbito alimenticio? Cabe objetar que el robo de las peras aparece como simple vehículo para introducir la reflexión sobre el pecado, sobre todo en su aspecto antropológico, sin vinculación propiamente con la concupiscencia de la carne. Pero hay que considerar varios datos. El primero que, al exponer la motivación del hecho, lo hace con imágenes que se ubican

31. Para una comprensión diferente de la nuestra, cf. H. KusCH, Studien über Augustinus, p. $150-152$.

32. Así en De vera religione. Cf. Estructura (II), en Estudio Agustiniano 33 (1998) 21.2526. Por supuesto, están comprendidas dentro de la concupiscencia de la carne también en Conf. 10,34,41-31,47:176-180.

33. «The metaphore of saciety is predominantely used for carnal cupidity, secundarily of the alternative satisfaction to be known from God» (cf. J.J. O'DONNELL, Augustine: Confessions, II, 107).

34. Cf. antes nota 22 .

35. «Sed non tenebatur modus ab animo usque ad animum, quatenus est luminosus limes amicitiae, sed exhalabantur nebulae de limosa concupiscentia carnis... et obnubilabant cor meum... ut non discerneretur serenitas dilectionis a caligine libidinis» (Conf. 2,2,2:18).

36. «Inualuerat super me ira tua, et nesciebam. Obsurdueram stridore catenae mortalitatis meae, poena superbiae animae meae...» (Conf. 2,2,2:18). «L'image employée ici mérite d'être remarquée: il s'agit du grincement de la chaîne du prisonnier, chaîne que lie Augustin à ce qui est mortel en lui, "mortalitatis meae", c'est a dire à son corps et à son sens» (M. Testard, La "superbia" dans les Confessions, p. 141). Cf. también 2,2,3:18-19: «... potens imponere lenem manum ad temperamentum spinarum a paradiso tuo seclusarum?». 
perfectamente en el ámbito de dicha concupiscencia. Así hay que entender el «hastío» de la justicia y la «saturación» de maldad ${ }^{37}$. El segundo se refiere a la descripción del hecho mismo. Al indicar que se llevaron enormes cantidades de peras, pero no para comerlas ellos, sino para echarlas a los cerdos, utiliza el término epulas, con el que probablemente hace referencia al rico epulón del evangelio (Lc 16,19-31), en el que la glotonería era tanto más condenable cuanto que tenía al mendigo Lázaro a la puerta. En todo caso, aunque poco, también comieron algo y no porque les urgiese satisfacer la natural necesidad del hambre ${ }^{38}$. Ahora bien, todo comer que no sirva a satisfacer tal necesidad el santo lo considera como manifestación de la concupiscencia de la carne 39. Además, el robo de las peras lo asocia a la voluptas, concepto clave en la reflexión sobre la misma concupiscencia ${ }^{40}$. Al respecto importa poco que lo haga para afirmar que no fue la voluptas que le podía proporcionar aquel fruto la que le movió a perpetrar el robo, como cabía esperar ${ }^{41}$. Por último, ya en el epílogo del libro, el Santo presenta, de un lado, la situación de penuria -regio egestatis-, el fruto que cosecha quien se deja arrastrar por la concupiscencia de la carne ${ }^{42}$, y de otro a Dios como la quies y la vita imperturbable, los dos valores que, por caminos errados, busca en ella el hombre ${ }^{43}$.

Parece claro, pues, que la armazón de C2 la componen dos manifestaciones de la concupiscencia de la carne, que constituyen las dos partes del libro. Pero afirmar eso no implica sostener que Agustín se presenta a sí mismo rendido a dicha concupiscencia en las dos manifestaciones indicadas. El hecho es cierto en referencia al ámbito de la sexualidad, pero no al alimenticio. En la guerra entablada, el joven ha sido derrotado en una batalla de la sexualidad,

37. «... nulla compulsus egestate nisi penuria et fastidio iustitiae et sagina iniquitatis» (Conf. 2,4,9:22).

38. «... et abstulimus inde onera ingentia non ad nostras epulas, sed uel proicienda porcis, etiamsi aliquid inde comedimus, dum tamen fieret a nobis quod eo liberet, quo non liceret» $(2,4,9: 22)$; «Nam decerpta proieci epulatus inde solam iniquitatem, qua laetabar fruens» $(2,6,12: 23)$.

39. Cf. Conf. 10,31,43-44:177-178.

40. Cf. nota anterior.

41. «... possem etiam solus, si satis esset committere illam iniquitatem, qua peruenirem ad uoluptatem meam, nec confricatione consciorum animorum accederet pruritum cupiditatis meae? Sed quoniam in illis pomis uoluptas mihi non erat, ea erat in ipso facinore, quam faciebat consortium simul peccantium» $(2,8,16: 25)$.

42. «... et factus sum regio egestatis» $(2,10,18: 26)$. Cf. De vera religione $54,104 \mathrm{CC} 32,254$, aunque dicha indigencia la reserva para el tiempo escatológico. Cf. Estructura (II), en Estudio Agustiniano 33 (1998) 47.

43. «Quies apud te est ualde et uita imperturbabilis» (Conf. 2,10,18:26). Cf. De uera religione 53,103 CC 32,253. Cf. Estructura (II), en Estudio Agustiniano 33 (1998) 41. 
pero se ha conservado incólume en la de la gula. El libro nos deja también un breve testimonio de la ambición mundana de Agustín, al señalar que sentía vergüenza de ser menos desvergonzado que los compañeros de la misma edad. Viendo que entre ellos el baremo de la gloria era el de la satisfacción del deseo carnal, la agradaba sucumbir a él no sólo por el placer, sino también por el prestigio que le procuraba 44 .

Dentro de los libros de la segunda terna, C6 parece asimismo estructurado sobre la concupiscencia de la carne. Dejando de lado la minibiografía de Alipio (7,11-10,17), en él se pueden establecer dos partes: una, hasta 7,11 ; otra, a partir de 11,18. La primera se caracteriza por los «encuentros» de Agustín en Milán: con su madre Mónica, recién llegada de África, con el obispo Ambrosio y con un mendigo en las calles de la ciudad lombarda; en la segunda domina el tema del matrimonio y la sexualidad.

Detengámonos brevemente en la primera parte. Sorprende que, como dato común, haga referencia a la actitud ante la comida/bebida de los tres personajes con los que se encuentra. La lista la encabeza la madre Mónica. De ella pone de relieve su devoto sometimiento a las normas establecidas en la ciudad por su obispo ${ }^{45}$ y su sobriedad en la comida y bebida ${ }^{46}$. En el caso concreto a que se refiere, el del culto a los mártires, su personal relación con la comida y bebida lo regulaba la piedad, no el placer ${ }^{47}$. Importante es tam-

44. «... ibam tanta caecitate, ut inter coetaneos meos puderet me minoris dedecoris, quoniam audiebam eos iactantes flagitia sua et tanto gloriantes magis, quanto magis turpes essent, et libebat facere non solum libidine facti uerum etiam laudis» (2,3,7:21). Cf. también 2,9,17:26. A nivel de reflexión, pero sin referirse directa e inmediatamente a sí mismo, dentro de C2 san Agustín alude a las tres concupiscencias en 2,5,10:22 (texto en nota 25), y en 2,6,13:23-24. Aunque esté refiriendo su lucha con un cuerpo del ejército adversario, no olvida que son tres. Al mismo tiempo, tampoco olvida poner de relieve la superbia que ocultaba el hurto de las peras, a cuya perpretación le movió no tanto el deseo de uoluptas, como el de una imitación perversa de Dios (cf. 2,6,14:24).

45. «Itaque, cum ad memorias sanctorum, sicut in África solebat, pultes et panem et merum attulisset atque ab ostiario prohiberetur, ubi hoc episcopum uetuisse cognouit, tam pie atque oboedienter amplexa est, ut ipse mirarer, quam facile accusatrix potius consuetudinis suae quam disceptatrix illius prohibitionis effecta est» $(6,2,2: 74)$.

46. «Non enim obsidebat spiritum eius uinulentia eamque stimulabat in odium ueri amor uini, sicut plerosque mares et feminas, qui ad canticum sobrietatis sicut ad potionem aquatam madidi nausiant: sed illa cum adtulisset canistrum cum sollemnibus epulis praegustandis et largiendis, plus etiam quam unum pocillum pro suo palato satis sobrio temperatum, unde dignationem sumeret, et si multae essent quae illo modo uidebantur honorandae memoriae defunctorum, idem ipsum unum, quod ubique poneret, circunferebat, quo iam non solum aquatissimo, sed etiam tepidissimo cum suis praesentibus per sorbitiones exiguas partiretur» $(6,2,2: 74)$.

47. «... quia pietatem ibi quaerebat non uoluptatem» $(6,2,2:: 74)$. 
bién el dato de que acudía con asiduidad a la Iglesia, a la fuente del agua que salta hasta la vida eterna, quedando suspendida de las palabras de san Ambrosio ${ }^{48}$. La mujer que era sobria en la comida y bebida materiales, alimentaba con profusión su espíritu con la palabra de Dios.

El segundo personaje a que hace referencia es san Ambrosio. También a propósito de él expone su relación con el alimento, tanto del cuerpo como del espíritu. En cuanto al primero, es parco en palabras; se limita a señalar su sobriedad, indicando que no tomaba más que lo necesario para su sustento ${ }^{49}$. Más espacio dedica al segundo. Poco antes ha dicho que él no podía conjeturar ni había experimentado los sabrosos deleites del pan divino que la boca oculta en su corazón rumiaba 50. Efectivamente, su espíritu lo alimentaba con la lectura 51. Su leer en voz baja le llamó la atención y se esfuerza por dar razones de tan raro proceder en aquellos tiempos 52 .

Tanto santa Mónica como san Ambrosio fueron ejemplares en su actitud frente a la bebida/comida. Esa faceta de la concupiscencia de la carne no hizo presa en ellos ${ }^{53}$. Caso distinto es el del tercer personaje que entra en escena, el mendigo con que topó en la calle cuando se disponía a pronunciar el discurso en alabanza del emperador. De él dice que estaba repleto de vino ${ }^{54} \mathrm{y}$ ebrio 55 . A la templanza de aquellos se contrapone el desenfreno de este, que, por otra parte, no se cuida de alimentar su espíritu.

Tema común: actitud ante la comida/bebida. Pero san Agustín ha hablado de otros, no de sí. Y se comprende. Cuando en C10 se examine a sí mismo a propósito de la concupiscencia de la carne en este ámbito, no halla mucho que reprocharse. Su delicadeza de conciencia le lleva a admitir que alguna vez se le cuela subrecticiamente el excederse algo en la comida, pero no en la

48. «... et studiosius ad ecclesiam currere et in Ambrosii ora suspendi, ad fontem salientis aquae in uitam aeternam» $(6,1,1: 73-74)$.

49. «... aut corpus reficiebat necessariis sustentaculis» $(6,3,3: 75)$.

50 . «... et occultum os eius, quod erat in corde eius, quam sapida gaudia de pane tuo ruminaret, nec coniecere noueram nec expertus eram» $(6,3,3: 75)$.

51. «... et lectione spiritum» $(6,3,3: 75)$.

52. «Sed cum legebat, oculi ducebantur per paginas et cor intellectum rimabatur, uox autem et lingua quiescebat... $\gg(6,3,3: 75)$.

53. «M(onnica) was to $\mathrm{A}$ (ugustine) no plaster saint, the more because the present passage in conf. has the effect of showing her lack of concupiscentia carnis... M. has he habit but not the concupiscence, hence the habit is easily broken» (J.J. O'DonNELL, Augustine: Confessions II,335). Ya en 5,9,17:66 había anticipado que era una viuda «casta y sobria», dos adjetivos que afirman su libertad frente a la concupiscencia de la carne.

54. «... saturum iocantem atque laetantem» $(6,6,9: 79)$.

55. «Et ille ipsa nocte digesturus erat ebrietatem suam» $(6,6,10: 80)$. 
bebida 56 . Esta confesión da razón de su proceder en C6, como antes en C2. El ámbito de la comida/bebida suele ser campo en que la concupiscencia plantea batalla y en el que, por tanto, se puede salir derrotado o vencedor. Suele ser, puede ser; no necesariamente es. Tal fue el caso de san Agustín: al menos la suya no fue una lucha encarnizada.

El Santo no tiene nada especial que decir de sí al respecto en esa etapa de su vida. Mas por razones de guión necesita introducir este campo de batalla y lo introduce. Importa poco que, de hecho, sirva como vía de paso hacia otros temas. Lo vimos en C2: el robo de las peras le sirvió para reflexionar sobre la naturaleza del pecado; lo acabamos de ver en C6: el ayuno y austeridad de Mónica le sirve para señalar cómo entró en una primera relación con san Ambrosio; el doble régimen alimenticio, físico y espiritual, del santo obispo lo utiliza para introducir el nuevo modo de lectura de la Escritura que el joven Agustín descubre escuchándole a él; la borrachera del mendigo, para introducir las reflexiones sobre la vanidad de sus ambiciones de entonces 57 .

Con el capítulo undécimo comienza, repetimos, la segunda parte, centrada en el ámbito de la sexualidad. En ella el Santo expone la perplejidad y las expectativas del momento: conseguir un cargo público, como la presidencia de una provincia, y casarse con una mujer con cierta disponibilidad económica ${ }^{58}$. Pero sorprende que en los capítulos que siguen todo verse en torno a la mujer, menos en cuanto compañera con quien compartir vida, que como medio necesario para saciar su apetito sexual ${ }^{59}$. De una parte, creía que sería extremamente desdichado, si hubiera tenido que renunciar a sus abrazos 60 .

56. «Ebrietas longe est a me...Crapula autem nonnumquam subrepit seruo tuo... ebriosus numquam fui» $(10,31,45: 178-179)$. Esta libertad frente al placer de la comida y bebida la proclama Agustín ya en los Soliloquios: «Sed omnino sive de cibu et potu, sive de balneis, caeteraque corporis voluptate nihil interroges; tantum habere appeto, quantum in valetudinis opem conferri potest» (I,10,17 PL 32, 879).

57. Al concluir la digresión que significa la minibiografía de Alipio, Agustín se presenta a sí y a sus amigos como tres bocas hambrientas que mutuamente se comunicaban el hambre y esperaban de Dios que les diese comida en el momento oportuno (Sal 144,15) $(6,10,17: 85)$. Pero aquí el santo habla en sentido figurado, lo que sale fuera de nuestro interés.

58. «Ecce iam quantum est, ut impetretur aliquis honor. Et quid amplius in his desiderandum? Suppetit amicorum copia: ut nihil aliud et multum festinemus, uel praesidiatus dari potest. Et ducenda uxor cun aliqua pecunia, ne sumptum nostrum grauet, et ille erit modus cupiditatis» $(6,11,19: 87)$.

59. Cf. nota 60 y 62 .

60. «Putabam enim me miserum fore nimis, si feminae priuarer amplexibus, et medicinam misericordiae tuae ad eandem infirmitatem sanandam non cogitabam, quia expertus non eram, et propriarum uirium credebam esse continentiam...» $(6,11,20: 87)$. Nótese que habla de una infirmitas y de la correspondiente medicina. 
De otra, discute con el amigo Alipio sobre la posibilidad de combinar la búsqueda de la sabiduría con el matrimonio ${ }^{61}$, pues sin este juzgaba no poder vivir ${ }^{62}$. Tal era su fuerza de persuasión que, aunque el amigo era entonces un ejemplo de castidad 63, acabó deseando el matrimonio, llevado de la curiosidad, no del deseo del placer ${ }^{64}$. Mientras lo que a Agustín le tenía cautivo y atormentaba era, en buena medida, la costumbre de saciar la insaciable concupiscencia, a Alipio le arrastraba a la cautividad el asombro que le causaba el amigo 65.

Los pasos siguientes fueron buscarse una joven con la que casarse en su momento ${ }^{66}$, despedir a la mujer con la que había convivido hasta entonces 67 y juntarse con otra, movido únicamente por la pasión carnal 68 .

61. «Prohibebat me sane Alipius ab uxore ducenda, cantans nullo modo nos posse securo otio simul in amore sapientiae uiuere... si id fecissem... Et ego resistebam illi exemplis, qui coniugati coluissent sapientiam et promeruissent Deum... A quorum ego quidem granditate animi longe aberam et deligatus morbo carnis mortifera suauitate trahebam catenam meam solui timens et quasi concusso uulnere repellens uerba bene suadentis tamquam manus soluentis... » (6,12,21:87-88). Adviértase la catena que apareció ya en Conf 2,2,2:18.

62. «Cum enim ille miraretur, quem non parui penderet, ita haerere uisco illius uoluptatis, et me affirmarem, ... coelibem uitam nullo modo posse degere...» $(6,12,22: 88)$. Pero añadiendo el objetivo por el que deseaba el matrimonio: «Neutrum enim nostrum, si quod est coniugale decus in officio regendi matrimonii et sucipiendorum liberorum, ducebat nisi tenuiter. Magna autem ex parte atque uehementer consuetudo satiandae insatiabilis concupiscentiae me captum excruciabat» (ib.).

63. «Erat enim ipse in ea re castissimus, ita ut mirum esset, quia uel experientiam concubitus ceperat in ingressu adulescentiae suae, sed non haeserat magisque doluerat et spreuerat et deinde iam continentissime uiuebat...» $(6,12,22: 88)$.

64. «... coeperat et ipse desiderare coniugium nequaquam uictus libidine talis uoluptatis, sed curiositatis...» $(6,12,22: 88)$.

65. «Magna autem ex parte atque uehementer consuetudo satiandae insatiabilis concupiscentiae me captum excruciabat, illum autem admiratio capiendum trahebat» $(6,12,22: 88)$.

66. «Et instabar impigre, ut ducerem uxorem. Iam petebam, iam promittebatur maxime matre dante operam, quo me iam coniugatum baptismus salutaris ablueret... Instabatur tamen, et puella petebatur... » $(6,13,23: 89)$. Digno de notar es la intervención de su madre. Parece como si quisiera redimirse del pecado de que la había acusado el hijo en C2: «Non fuit cura meorum ruentem excipere me matrimonio, sed cura fuit tantum, ut discerem sermonem facere... » (2,2,4:19; cf. también 2,3,8:21).

67. «... et auulsa a latere meo tamquam impedimento coniugii cum qua cubare solitus eram, cor, ubi adherebat, concisum et uulneratum mihi eiat.et trahebat sanguinem» $(6,15,25: 90)$.

68. «At ego infelix, nec feminae imitator, dilationis impatiens, tamquam post biennium accepturus eam quam petebam, quia non amator coniugii sed libidinis seruus eram, procuraui aliam, non utique coniugem, quo tanquam sustentaretur et perduceretur uel integer uel auctior morbus animae meae satellitio perdurantis consuetudinis in regnum uxorium» $(6,15,25: 90)$. A estos datos hay que añadir todavía que el proyecto de vida filosófica se hizo añicos y fue desechado por motivo de las mujeres que unos tenían y otros pensaban tener $(6,14,24: 89)$. 
Los datos concretos señalados no son más que los síntomas de una situación que él describe como un hallarse hundido en un profundo abismo de placeres carnales ${ }^{69}$. Situación que contaba en buena medida con un soporte ideológico. De entre todos los moralistas de la antigüedad, el joven profesor habría dado la palma a Epicuro, si no le hubiese retenido su fe en la supervivencia del alma respecto del cuerpo 70 .

Por último, en el capítulo conclusivo, igual que en C2, Dios es presentado como quies -en este caso exactamente requies-, esto es, lo que el hombre busca mediante la satisfacción de la concupiscencia de la carne ${ }^{71}$.

Volviendo a la imagen del ejército, en C6 el cuerpo que entra en batalla es la concupiscencia de la carne con dos de sus divisiones: la comida/bebida y la sexualidad. La primera rehusa enfrentarse a Agustín, sale derrotada en santa Mónica y san Ambrosio y vencedora en el mendigo. A nuestro objetivo sirve el simple hecho de que esté presente, independientemente de que luche o no y del resultado de sus luchas. La segunda, por el contrario, tiene avasallado a Agustín, a la vez que ha sufrido una derrota en toda regla en san Ambrosio 72 y parcial en Alipio. Es esta «división» la que lleva el peso del combate en la segunda parte del libro, como en la primera la de la comida/bebida. Decimos que lleva el peso del combate, porque en una y otra parte, aparece flanqueada por otro cuerpo, el de la ambición ${ }^{73}$. Pero de su presencia en el relato se puede decir que es sólo testimonial.

Como conclusión a esta unidad, no cabe sino afirmar el paralelismo neto entre C2 y C6, aunque con estructura invertida. En C2 la batalla comienza en el campo de la sexualidad y concluye en el de la comida; en C6, en cambio, la

69. «Nec me reuouabat a profundiore uoluptatum carnalium gurgite nisi metus mortis et futuri iudicii tui, qui per uarias opiniones, numquam tamen recessit a pectore meo» $(6,16,26: 90)$.

70. «Et disputabam cum amicis meis Alypio et Nebridio de finibus bonorum et malorum, Epicurum accepturum fuisse palmam in animo meo, nisi ego credidissem post mortem restare animae uitam et tractus meritorum, quod Epicurus credere noluit» $(6,16,26: 90)$.

71. «Vae animae audaci, quae sperauit, si a te recessisset, se aliquid melius habituram! Versa et reuersa in tergum et in latera et in uentrem, et dura sunt omnia, et tu solus requies» $(6,16,26: 91)$. Cf. nota 43 .

72. «Coelibatus tantum eius mihi laboriosius uidebatur» $(6,3,3: 75)$.

73. Cf. para la primera parte, $6,6,9: 79$ («Inhiabam honoribus, lucris, coniugio») y para la segunda 6,11,19 (textos en nota 58). La particularidad de uno y otro consiste en que en ellos la concupiscencia de la carne o cupiditas uoluptatis y la ambición no aparecen acompañadas de la concupiscencia de los ojos o curiosidad, sino de la avaricia. Se trata de una segunda terna, distinta sólo parcialmente de la ofrecida por 1 Jn 2,16. Cf. también 2,5,10:22 (texto en nota 25), aunque la formulación del texto permite entender la primera frase tanto de la concupiscencia de los ojos (species est pulchris corporibus) como de la avaricia (et auro et argento). 
batalla comienza en el campo de la comida/bebida y concluye en el de la sexualidad. En ambos libros Agustín aparece derrotado en el campo de la sexualidad e incólume en el de la comida/bebida. La mención de este campo, sin embargo, le sirve en un libro y en otro para introducir otros temas, como ya se indicó.

Un detalle nos afianza en el paralelismo, en el sentido expuesto, entre C2 y C6. De los seis libros que constituyen la que hemos denominado Sección B, sólo en esos dos se hace mención de uno y otro campo de batalla 74 .

Si ahora volvemos los ojos a la Regla, es fácil advertir la coincidencia con los capítulos tercero y cuarto de la misma, que regulan respectivamente el régimen alimenticio y el régimen sexual de los siervos de Dios. Es la que hemos venido denominando «unidad segunda», como al conjunto de los libros cuarto y sexto. Un esquema permitirá advertir con toda claridad tal coincidencia:

C2: sexualidad ( $1^{\mathrm{a}}$ parte) y alimento ( $2^{\mathrm{a}}$ parte).

C6: alimento, físico y espiritual ( $1^{\mathrm{a}}$ parte), y sexualidad ( $2^{\mathrm{a}}$ parte).

Regla: alimento físico (III,1.3-5) y espiritual (III,2), y sexualidad (IV).

\subsection{Unidad primera (C3 y C7)}

La unidad primera en nuestra terminología se refiere al ámbito específico de la cupiditas curiositatis o de la concupiscencia de los ojos. Dentro de ella hay que encuadrar C3 y C7.

Volviendo a la imagen militar utilizada con anterioridad, C3 presenta, de entrada, los tres «cuerpos» del único ejército que declaró la guerra al joven Agustín, como la declara a todo hombre. Dichos «cuerpos» corresponden a las tres concupiscencias, cuya obra devastadora aparece ya en los tres primeros capítulos 75 . Pero el que lleva el lleva el peso de la batalla en este libro es el correspondiente a la cupiditas curiositatis o concupiscencia de los ojos. Una

74. Nos referimos a su realidad física. Es cierto que al capo de la sexualidad hace referencia también al comienzo de $\mathrm{C} 3$ y $\mathrm{C} 4$, pero de ello ya hemos dado explicación. Simples alusiones al aspecto sexual se encuentran, sin embargo, en 4,7,12:46.

75. Cf. nota 26. El motivo de las tres concupiscencias vuelve a aparecer; a nivel de reflexión solamente, en el capítulo octavo: «... Haec sunt capita iniquitatis, quae pullulant principiandi et spectandi et sentiendi libidine, aut una, aut duabus earum aut simul omnibus...» $(3,8,16: 35-36)$. 
batalla en que Agustín cae derrotado sin paliativos y cuya descripción, incluidas las causas, alcanza su punto culminante en el capítulo sexto, respecto del cual los anteriores son preparación y los siguientes desarrollo y explicitación.

La preparación comienza en el capítulo cuarto, en que san Agustín narra su lectura del Hortensio de Cicerón y la pasión por la Sabiduría que suscitó en su interior. Una pasión que le condujo, primero, a leer la Escritura católica ${ }^{76} \mathrm{y}$, luego, a alistarse en la secta maniquea en la categoría de «oyente». No se trata de pasos simplemente sucesivos en el tiempo, puesto que entre ellos hay relación de dependencia estrecha. El joven se adhirió a los maniqueos como consecuencia (itaque) del rechazo de la Escritura católica. En la condición actual del hombre, el papel de la Escritura es fundamental para conseguir el auténtico conocimiento de la Verdad, de Dios. Quien la rechaza en todo o en parte o quien no la interpreta adecuadamente se cierra él mismo el camino hacia la Verdad.

Para presentar su caída en la secta, utiliza, no cabe duda, categorías habituales en él cuando se ocupa de la concupiscencia de los ojos. Recordemos que esta no es otra cosa que la «perversión» del deseo de conocimiento pleno y auténtico, el de la Verdad. Dicha concupiscencia no conoce más órgano para la percepción de la misma que los sentidos exteriores, ni, en consecuencia, más verdad que la que directa o indirectamente le ofrecen ellos. El hombre que sucumbe a ella olvida que la Verdad es inmutable y eterna, perceptible sólo con el ojo de la inteligencia desde el interior del hombre, y se contenta con espectáculos exteriores, imágenes sensibles y creaciones de la propia imaginación, todo ello simples «ilusiones» 77 .

Detrás de la caída del joven Agustín en el maniqueísmo está su amor por la Sabiduría, su anhelo de Verdad. En las Confessiones, el santo la personifica y la apostrofa, recordando cuán íntimamente suspiraba por ella desde lo más íntimo de su corazón, cuando los maniqueos le pronunciaban su nombre con multiplicada frecuencia, no obstante se tratase, en ellos, sólo de un sonido 78. Esa hambre de verdad fue lo que le llevó a sentarse en la mesa de los

76. Cf. P. DE LUIS, No me pareció digna de ser comparada con la dignidad de Tulio (Confessiones III,5,9), en Jornadas Agustinianas. Con motivo del XVI Centenario de la conversión de san Agustín. Madrid 22-24 de abril de 1987, Valladolid 1988, 49-70.

77. Cf. De uera religione 49,94-51,101a y Estructura (II), en Estudio Agustiniano 33 (1998) 11-19. Para conocer qué entiende san Agustín por concupiscencia de los ojos, con sus manifestaciones concretas, cf. Conf. 10,35,54-57:184-186; Sermo 112,3,3-5,5 PL 38,644-646. Sobre las «ilusiones» cf. En. in psalmum 37, 11 CC 38,389-390.

78. «O ueritas, ueritas, quam intime etiam tunc medullae animae meae suspirabant tibi, cum te illi sonarent mihi frequenter et multipliciter sola uoce et libris multis et ingentibus» $(3,6,10: 31)$. 
maniqueos. Pero en vez de recibir el alimento que su mente ansiaba, Dios, no recibió más que puras creaciones de la imaginación ${ }^{79}$. Reconoce que su error consistió en no haber buscado a Dios con la inteligencia, sino con los sentidos de la carne. Error craso, habida cuenta de que Dios es más interior que lo más íntimo del hombre y está por encima de lo más elevado de él. O con otras palabras, haber vagado fuera de sí, bajo el imperio del sentido carnal de la vista, rumiando en su interior tales cosas cuales por él devoraba. Por caminar fuera de sí topó con la mujer procaz y falta de sabiduría (Prov 9,17) que le sedujo ${ }^{80}$. Háblese de huida de la interioridad o de caída en la exterioridad, da lo mismo. Son dos caras de una misma moneda.

Si los dos capítulos que preceden a este sexto tienen el valor de preparación, los capítulos siguientes, del séptimo al noveno, ofrecen la confirmación y las consecuencias, con ejemplos concretos, de la derrota sufrida ${ }^{81}$.

Anhelando y buscando la Verdad, acepta como Verdad las creaciones de la imaginación maniquea (phantasmata); debiendo buscarla con la inteligencia, la busca con los sentidos de la carne; en lugar de refugiarse en el propio interior, donde mora la Verdad, no hace sino vagar por el exterior: he aquí la explicación antropológica de por qué Agustín cayó en el maniqueísmo; no se podía hacer más breve descripción de lo que él considera concupiscencia de los ojos ${ }^{2}$. Pero como ya vimos en $\mathrm{C} 2$, aunque en el libro ocupa la máxima atención el enfrentamiento -y subsiguiente derrota-con la concupiscencia de los ojos, las otras dos concupiscencias aparecen de nuevo en el cuerpo del libro, con presencia sólo testimonial ${ }^{83}$.

79. «Et apponebantur mihi in illis ferculis phantasmata splendida... Quanto ergo longe es a phantasmatis illis meis, phantasmatis corporum, quae omnino non sunt...» $(3,6,10: 31.32)$.

80. «... cum te non secundum intellectum mentis,... sed secundum sensum carnis quaererem. Tu autem eras interior intimo meo et superior summo meo... Offendi illam mulierem audacem, inopem prudentiae, aenigma Salomonis... (Prov 9,17). Quae me seduxit, quia inuenit foris habitantem in oculo carnis meae et talia ruminantem apud me, qualia per illum uorassem» $(3,6,11: 33)$.

81. Se adhirió al maniqueísmo buscando la Verdad, pero no logró más que ignorancia. Los verbos que la indican se suceden cada pocas líneas: 3,7,12-14:33-34 (línea 1: nesciebam; 1 . 6: ignarus; 1. 7: non noueram; 1. 10: non noueram; 1. 16: ignorabam; 1. 16: non noueram; 1. 48: nesciebam; 1. 53: non intuebar) 3,10,18:37 (1. 1: nesciens). Ignorancia referida en todos los casos a realidades espirituales, entre ellas la naturaleza del ser de Dios.

82. Cf., entre otros textos, De vera religione 49,94-52,101 CC 32,248-253; Conf 10,35,5457:184; Sermo 112,3-5.7: Revue Bénedictine 76 (1966) 46-53.

83. De hecho, entran en la reflexión del santo, pero sin ponerlas en relación directa e inmediata con su propia persona. Cf. 3,8,15-9,17:35-37. A propósito de la concupiscencia de la carne en $\mathrm{C} 2$ indicamos que tenía su fuente última en el orgullo del hombre (cf. nota 36). Lo mismo hay que decir aquí de la concupiscencia de los ojos. Si cayó en ella fue porque el orgulo le impidió penetrar en el sentido de la Escritura: «Tunc enim tumor meus refugiebam 
En cierto sentido $\mathrm{C} 7$ representa, respecto de $\mathrm{C} 3$, lo mismo que $\mathrm{C} 6$ respecto de C2. Igual que en C6, también en C7 falta la referencia inicial a la derrota ante las tres concupiscencias con que abrían tanto $\mathrm{C} 2$ como $\mathrm{C} 3$. El «cuerpo» del ejército adversario a que san Agustín relata en C7 haberse enfrentado de modo particular es, de nuevo, la concupiscencia de los ojos. En otro sentido, sin embargo, no se puede establecer la comparación, pues tanto en C2 como en C6 Agustín se manifiesta sometido a la misma concupiscencia, mientras que en C7 se libera de la esclavitud confesada en C3.

C7 representa la liberación del espíritu del joven Agustín ${ }^{84}$. El libro comienza señalando, ya en su primer capítulo, de qué necesitaba ser liberado: de la carga que arrastraba de su período maniqueo. La más pesada, la que más le oprimía, era la falsa imagen que tenía de Dios, que concebía como una realidad corpórea, designada de nuevo mediante el término phantasma ${ }^{85}$. En su espíritu perdura, en lo fundamental, lo que encontramos en C3: en lugar de la Verdad, una ficción; la exterioridad sigue ocupando el lugar que, respecto del conocimiento de la Verdad, compete a la interioridad; los sentidos, el de la inteligencia. Los capítulos siguientes abundan en la descripción más detallada de la imagen -procedente del mundo de los sentidos-, que se hacía de Dios, pero especificar tales detalles no aporta nada especial a lo que centra nuestro interés.

La segunda parte del libro, que comienza con el capítulo noveno, se abre con el cambio decisivo y radical que experimentó Agustín en aquel momento. Como resultado de la lectura de «los libros de los platónicos» la exterioridad cedió el puesto a la interioridad ${ }^{86}$ y los sentidos a la inteligencia 87 como

modum eius et acies mea non penetrabat interiora eius... ego dedignabar esse paruulus et turgidus fastu mihi grandis uidebar» (3,5,9:31). Lo mismo en C7; cf. nota 91.

84. Cf. G. MADEC, La délivrance de l'esprit (Confessions VII), en «Le Confessioni di Agostino d'Ippona. Libri VI-IX, Palermo 1985, pp. 45-69. El espíritu es el campo de acción de la concupiscencia de los ojos, mientras que el cuerpo es el de la concupioscencia de la carne y la condición social del hombre el de la ambición mundana.

85. «Clamabat uiolenter cor meum aduersus omnia phantasmata mea et hoc uno ictu conabar abigere circumuolantem turbam inmunditiae ab acie mentis meae: et uix demota in ictu oculi ecce conglobata rursus aderat et inruebat in aspectum meum et obnubilabat eum, ut quamuis non forma humani corporis, corporeum tamen aliquid cogitare cogerer...» (Conf. 7,1,1:92). Sobre el concepto de phantasma, cf. I. Bochet, Saint Augustin et le desir de Dieu, Paris 1989 , p. 49, n.2.

86. «Et inde admonitus redire ad memet ipsum intraui in intima mea duce te et potui, quoniam factus es adiutor meus» $(7,10,16: 103)$.

87. «Intraui et uidi qualicumque oculo animae meae supra eundem oculum animae meae, supra mentem meam lucem incommutabilem, non hanc uulgarem et conspicuam omni carni 
medio de percepción de la Verdad auténtica 88 , ya no ficciones en su lugar 89. Dios es descubierto en su realidad puramente espiritual ${ }^{90}$.

Si la primera parte del libro hacía patente el sometimiento a los dictámenes de la concupiscencia de los ojos en el problema del conocimiento de Dios, la segunda expone cómo sacudió su yugo. Agustín descubrió el único lugar adecuado donde es posible conocer la Verdad (la propia interioridad), el órgano adecuado para conocerla (la propia inteligencia) y su auténtica naturaleza (espiritual) ${ }^{91}$. El libro no ofrece referencia clara a ninguna de las otras dos concupiscencias.

Podemos establecer ya la comparación con la unidad primera de la Regla. La relación entre C3 y C7 con ella no salta a la vista como acontecía en la unidad segunda, anteriormente considerada. Pero en la medida en que se acepte la interpretación que hemos dado de ella desde el cotejo con la res-

nec quasi ex eodem genere grandior erat, tamquam si ista multo multoque clarius claresceret totumque occuparet magnitudine» $(7,10,16: 103)$.

88. «Qui nouit ueritatem, nouit eam, et qui nouit eam, nouit aeternitatem. O aeterna ueritas et uera caritas et cara aeternitas! Tu es Deus meus» $(7,10,16: 103)$.

89. «Et mirabar, quod iam te amabam, non pro te phantasma...» (Conf. 7,17,23::107). De las once veces que san Agustín habla en las Confessiones de sus propios phantasmata, ocho aparecen en los dos libros examinados: cinco en C3 (3,6 [cuatro veces] y 3,7), y tres en C7 (1,1 y 17,23 [dos veces). La gran mayoría, pues. Las otras presencias en 4,4,9.12; 5,9,16 y 9,3,6.

90. Los importantes cambios que se produjeron en su comprensión metafísica de la realidad, los expone en los capítulos siguientes (Cf. 7,11,17:104ss).

91. Aquí, como en otros lugares ya vistos, el Santo pone de relieve la vinculación con la superbia en la primera de las acepciones indicada anteriormente (cf. nota 17). De un lado, la causa de seguir sometido a la concupiscencia de los ojos estaba en la superbia. Esta le había hinchado el ojo interior y no podía ver la Verdad como es: «Sed cum superbe contra te surgerem et currerem aduersus Dominum in ceruice crassa scuti mei, etiam ista infima supra me facta sunt et premebant... Ipsa occurrebant undique aceruatim et conglobatim cernenti, cogitanti autem imagines corporum ipsae opponebantur redeunti... Et haec de uulnere meo creuerant, quia humiliasti tamquam uulneratum superbum, et timore meo separabar abs te et nimis inflata facies claudebat oculos meos» $(7,7,11: 100)$. De otro lado, la misma superación de dicha concupiscencia le llevó a la superbia, el orgullo de los filósofos neoplatónicos, al no aceptar la encarnación del Verbo ni, por tanto, la Escritura que la proclama. «Sed tunc lectis Platonicorum illis libris posteaquam inde admonitus quaerere incorpoream ueritatem inuisibilia tua per ea quae facta sunt intellecta conspexi et repulsus sensi, quid per tenebras animae meae contemplari non sinerer... Garriebam plane quasi peritus esset et, nisi in Christo, saluatore nostro, uiam tuam quaererem, non peritus, sed periturus essem. Iam enim coeperam uelle uideri sapiens plenus poena mea et non flebam, insuper et inflabam scientia» (7,20,26:109-110). También en De uera religione aparece, en el ámbito de la problemática de la concupiscencia de los ojos, la referencia a la Escritura como camino concreto puesto por Dios para llegar a la Verdad (cf. De uera religione 50,98-51,100 CC 32,250-252). 
pectiva unidad de De vera religione 92 y de $\mathrm{C} 10{ }^{93}$, las dudas se esfumarán. En su parágrafo segundo, el legislador ordenaría evitar los «espectáculos exteriores» que puedan entorpecer la oración; en el tercero reclamaría que no la enturbien los «espectáculos» que, a través de los sentidos, hayan penetrado en el corazón; en el cuarto pediría un uso correcto de la Escritura, digiriéndolo al fin para el que se ella dio. Tanto la Regla, en su unidad primera, como C3 y C7, maneja los mismos conceptos: Dios (Verdad/Belleza), exterioridad, interioridad, Escritura.

Pero afirmada esa convergencia, hay que señalar las divergencias. En efecto, aunque los conceptos fundamentales son los mismos, la aplicación no es idéntica. Al respecto procede recordar lo dicho al establecer la comparación del De vera religione con la Regla. De una parte, C3 y C7 se refieren a un contexto de fe y conocimiento de Dios, mientras que en la Regla el contexto es el de la oración y el trato con Dios; de otra, C3 y C7 son textos narrativos, mientras que la Regla es un texto legislativo.

Traducido en esquema, he aquí el resultado de la comparación:

C3 : papel de la Escritura; paso de la interioridad a la exterioridad y adoración de phantasmata.

C7 : paso de la exterioridad a la interioridad y liberación de los phantasmata; papel de la Escritura.

Regla: huir de la exterioridad (R II,2); purificar el corazón [de vanae cogitationes o phantasmata] (R II,3); [no torcer la función de la Escritura (R II,4)].

\subsection{Unidad tercera (C4 y C5).}

La unidad tercera corresponde a la ambición mundana. Dentro de ella encuadramos $\mathrm{C} 4$ y $\mathrm{C} 5$.

Las diversas manifestaciones de dicha concupiscencia marcan la estructura de ambos libros. La vinculación entre ellos y la ambición mundana no resulta tan clara como entre las otras concupiscencias y los respectivos libros, pero no nos queda duda al respecto. De una parte lo pide la lógica, de otra el texto aporta suficientes datos que lo apoyan.

92. Cf. Estructura (II), en Estudio Agustiniano 33 (1998) 21-25.

93. Cf. Estructura (III), en Estudio Agustiniano 33 (1998) 231-234. 
Comenzamos con C4. Prescindimos de los capítulos introductorios de que ya nos ocupamos anteriormente. En el resto del libro san Agustín refiere cuatro hechos sobre los que reflexiona: su afición a la astrología, la muerte del amigo, la composición del libro De pulchro et apto que dedica a Hierio, y sus lecturas.

A propósito de la astrología pone el acento en lo que implica: liberar al hombre de toda responsabilidad del pecado y cargarla sobre Dios mismo, actitud por la que recibe el calificativo de «podredumbre orgullosa» ${ }^{94}$. Pero el orgullo aquí es actitud «perversa» frente a Dios, no frente a los hombres ${ }^{95}$. No cabe contarlo como manifestación de la ambición mundana. Pero a continuación indica que el procónsul y médico Vindiciano había puesto una corona, ganada en un concurso, sobre su cabeza enferma. Enfermedad de la que sólo podía sanarle Dios, que resiste a los orgullosos, pero da su gracia a los humildes (Sant 4,6) ${ }^{96}$. El orgullo de que aquí hace mención puede tener su origen en su creencia en la astrología, o puede tenerlo en el triunfo cosechado sobre los demás pretendientes a la corona. En este caso, estaríamos ante una manifestación propia de la tercera concupiscencia ${ }^{97}$.

Más interesante para nuestro tema resulta el relato de la muerte del amigo, que, con las reflexiones que suscita al santo, ocupa buena parte del libro ${ }^{98}$. Es el mismo san Agustín quien presenta su relación con el amigo antes de morir como una forma de dominio sobre él. No lo afirma explícitamente, pero se deduce de su ponderación de la libertad con que el amigo le dijo que si quería seguir siéndolo suyo, debería cesar de mofarse del bautis-

94. "Quam totam illi salubritatem interficere conantur, cum dicunt: "De caelo tibi est ineuitabilis causa peccandi" et "Venus hoc fecit aut Saturnus aut Mars", scilicet ut homo sine culpa sit, caro et sanguis et superba putredo, culpandus sit autem caeli ac siderum creator et ordinator» $(4,3,4: 41)$.

95. «Ce text rend un son étonnamment moderne. A la manière de certains psychologues ou psychiatres de nous jours, ces charlatans "déculpabilisaient leurs clients, en invocant un déterminisme du comportement, "ineuitabilis causa peccadi", "une inévitable cause de pécher", qu'ils éxplicaient alors par le Ciel: Vénus, Saturne ou Mars. Saint Augustin, qui voit que l'on transfère ainsi la responsabilité du mal, del homme a Dieu, entendre rendre a l'homme son péché et à Dieu le jugement misericordieux" (M. TESTARD, La "superbia" dans les Confessions, p. 147).

96. «Erat eo tempore uir sagax, medicinae artis peritissimus... qui pro consule manu sua coronam illam agonisticam imposuerat illi non sano capiti meo, sed non ut medicus. Nam illius morbi tu sanator, qui resistis superbis, humilibus autem das gratiam» (4,3,5:42).

97. Esta interpretación da M. Testard: «Sur cette appellation générale des "superbi"... il fait reconnaître le jeune Augustin en tant que professeur orgueilleux, avide de succès, qui venait de participer à un concurs et que Vindicianus coronnait» (La "superbia" dans les Confessions, p. 148).

98. Cf. $4,4,7-12,19: 43-50$ 
mo que había recibido en estado de inconsciencia 99 . Del texto se puede colegir efectivamente que el santo le juzgaba esclavizado a sí mismo. De ahí que creyera que, como hombre sin libertad propia, aceptaría sin más lo que él le propusiera. Ello explica la extrañeza que le produjo ver que el amigo actuaba como persona totalmente libre que no se dejaba subyugar. El calificar tal libertad como repentina muestra que antes carecía de ella y, por tanto, podía ser tenido por un esclavo. ¿De quién? Del amigo Agustín, sin duda ${ }^{100}$. Pero, quizá, la conciencia que tenía el joven Agustín de dominar sobre el amigo queda reflejada mejor que en otro lugar en su afirmación de que, lleno de estupor y de turbación, difirió todas sus reacciones hasta que el amigo convaleciera del todo y, con la salud, recuperara las fuerzas, puesto que entonces podría hacer con él lo que quisiera 101.

El relato siguiente se ocupa de la primera obra escrita por él, el De pulchro et apto ${ }^{102}$. El hecho le sugiere también abundantes reflexiones, buena parte de las cuales parten de la circunstancia de habérselo dedicado al rhetor Hierio, persona a la que no conocía más que de oídas ${ }^{103}$. El santo pone especial énfasis en dar razón de ese comportamiento un tanto extraño: no era otra que el deseo de recabar un elogio de él, deseo que ahondaba sus raíces en el orgullo 104 .

Por último, en conexión con el contenido del De pulchro et apto, nos introduce en sus lecturas de aquel período. Reconoce su extraordinaria capa-

99. «... temptaui apud illum inridere, tamquam et illo inrisuro mecum baptismum, quem acceperat mente atque sensu absentissimus. Sed tamen iam se accepisse didicerat. At ille ita me exhorruit ut inimicum admonuitque mirabili et repentina libertate, ut, si amicus esse uellem, talia sibi dicere desinerem» $(4,4,8: 44)$.

100. De hecho, él había torcido su voluntad para llevarle al maniqueísmo: «... deflexeram eum in superstitiosas fabellas et pernitiosas...» $(4,4,7: 43)$.

101. «Ego autem stupefactus atque turbatus distuli omnes motus meos, ut conualesceret prius essetque idoneus uiribus ualetudinis, cum quo agere possem quod uellem. Sed ille abreptus dementiae meae, ut apud te seruaretur consolationi meae: post paucos dies me absente repetitur febribus et defungitur» (4,4,8:44). Hemos puesto un quizá porque todo depende de la traducción que se dé al cum quo agere possem quod uellem. Los autores suelen traducir el agere por «discutir», pero no cabe excluir totalmente el significado de «hacer» (cf. $5,7,13: 64 ; 5,8,14: 64)$. De ser así las cosas, adviértase la ironía que significa el esperar que recupere la totalmente salud para tratarle como un esclavo, cosa que no consigue cuando el amigo está convaleciente. En una carne débil el espíritu mantiene la libertad, gracias al don divino recibido en el bautismo.

102. Cf. 4,13,20-15,27:50.

103. Cf. 4,14,21-23:51-52.

104. «At ille rhetor ex eo erat genere, quem sic amabam, ut uellem me esse talem; et errabam typho et circunferebar omni uento... Et magnum quiddam mihi erat, si sermo meus et studia mea illi uiro innotescerent: quae si probaret, flagrarem magis; si autem improbaret, sauciaretur cor uanum et inane soliditatis tuae...» $(4,14,23: 52)$. 
cidad intelectual que le permitía entender por sí solo cuantos libros caían en sus manos. Incluso algunos que otros apenas lograban comprender tras esmeradas explicaciones por parte de competentes profesores ${ }^{105}$. La forma de expresarse denota la autocomplacencia que sentía al respecto 106.

Si dejamos de lado el dato referente a su afición a la astrología, por ambiguo para nuestro objetivo, podemos sintetizar el propio mundo interior que san Agustín deja trasparentar de los hechos que narra: afán de dominio (sobre el amigo), deseo de alabanzas (de un personaje célebre como Hierio), autocomplacencia personal (por su capacidad intelectual). Ahora bien, toda persona que conozca C10 advertirá aquí los tres puntos en que Agustín concreta la tercera concupiscencia, la ambición humana, referida a sí mismo ${ }^{107}$. Pero podemos ir todavía más lejos. Cuando el santo examina su conciencia respecto al deseo de alabanzas, señala que le agradan estas, pero no todas. Tanto en C10 como en C4 indica que estas le complacen sólo si vienen de personas que las tributan con criterio válido ${ }^{108}$. Asimismo, tanto en $\mathrm{C} 10$ como en C4 indica cómo el que le rehusasen la alabanza o disminuía su gozo o él

105. «Et quid mihi proderat, quod annos natus ferme uiginti, cum in manus meas uenissent Aristotelica quaedam, quas appellant decem categorias -quarum nomine, cum eas rhetor Carthaginensis, magister meus, buccis typho crepantibus commemoraret et alii qui docti habebantur, tamquam in nescio quid magnum et diuinum suspensus inhiabam- legi eas solus et intellexi? Quas cum contulissem cum eis, qui se dicebant uix eas magistris eruditissimis non loquentibus tantum, sed multa in puluere depingentibus intellexisse, nihil inde aliud mihi dicere potuerunt, quam ego solus apud me ipsum legens cognoueram?» (4,16,28:54).

106. El quid mihi proderat, referido a lecturas de diverso signo en que salía a relucir su condición de superdotado, de lo que estaba orgulloso, se convierte en un estribillo en el último capítulo $(4,16,28$. 29. 30 [2x]. 31 [2x]:54-55)). La autocomplacencia que debió experimentar se oculta bajo estos textos: «Quidquid de arte loquendi et disserendi intellexi, quidquid de dimensionibus figurarum et de musicis et de numeris sine magna difficultate nullo homine tradente intellexi... » $(4,16,30: 55)$. «Non enim sentiebam illas artes etiam ab studiosis et ingeniosis difficillime intellegi, nisi cum eis eadem conabar exponere et erat ille excellentissimus in eis, qui me exponentem non tardius sequeretur» (ib.). La crítica del ya obispo Agustín que se esconde bajo el quid mihi proderat refleja ese sentimiento de autocomplacencia que le embargó tiempos atrás.

107. Cf. En él la consideración de la ambición mundana se extiende por cuatro capítulos (36-39), que se refieren específicamente a las siguientes manifestaciones: afán de dominar (cap. 36); deseo de alabanzas (cap. 37-38); la autocomplacencia (cap. 39). Cf. Estructura (III), en Estudio Agustiniano 33 (1998) 238-242.

108. «Quid nisi delectari me laudibus? Sed amplius ipsa ueritate quam laudibus. Nam si mihi proponatur, utrum malim furens aut in omnibus rebus errans ab omnibus hominus laudari an constans et in ueritate certissimus ab omnibus uituperari, uideo quid eligam» $(10,37,61: 188)$. «Non autem uelle ita laudari... me ut histriones, quamquam eos et ipse laudarem..., sed eligens latere quam ita notus esse...» $(4,14,21)$. Adviértase en ambos textos la presencia del verbo eligere. El ejemplo es distinto, pero la idea de fondo es la misma: no le complacía cualquier alabanza. 
mismo se derrumbaba ${ }^{109}$. Paralelismos existen también entre ambos libros respecto de la autocomplacencia. Según C10, los autocomplacientes consigo mismos poseen los bienes de Dios como si fueran propios ${ }^{110}$, reproche que se hace a sí mismo el Santo en C4, al afirmar que disfrutaba con las artes liberales, pero ignoraba de dónde procedía cuanto en ellas hallaba de verdadero y cierto, y al no ofrecer sacrificio a Dios por la vivacidad de la propia inteligencia, que había recibido de él ${ }^{111}$.

En síntesis, en C4 san Agustín narra cómo perdió todas las batallas frente a las diferentes divisiones del tercer «cuerpo» del ejército enemigo. Se dejó subyugar por el afán de dominio sobre sus iguales, por el ansia de ser alabado, por la autocomplacencia por dones que le habían sido regalados. Los otros dos «cuerpos» del ejército cubren los flancos al que lleva la batalla, pues en sus parcelas ya tienen subyugado a Agustín. Su presencia en el libro es mínima. En cuanto a su sometimiento a la concupiscencia de la carne, sólo hallamos una brevísima alusión 112; algo mayor es la referencia a su sumisión a la de los ojos, muy breve en relación con la muerte del amigo ${ }^{113}$ y un poco más detenidamente en el contexto de su reflexión sobre el De pulchro et apto ${ }^{114}$.

109. «Verumtamen nollem, ut uel augeret mihi gaudium cuiuslibet boni mei suffragatio oris alieni. Sed auget, fateor, non solum, sed et uituperatio minuit. Et cum ista miseria mea perturbor...» $(10,37,61: 188)$. «Et magnum quiddam mihi erat, si sermo meus et studia mea illi uiro innotescerent; quae si probaret, flagrarem magis; si autem improbaret, sauciaretur cor uanum et inane soliditatis tuae» $(4,14,23: 52)$.

110. «Intus... est aliud in eodem genere temptationis malum, quo inanescunt qui placent sibi de se... Sed sibi placentes multum tibi displicent non tantum de non bonis quasi bonis, uerum etiam de bonis tuis quasi suis...» (Conf. 10,39,64:190).

111. «Et quid mihi proderat, quod omnes libros artium, quas liberales uocant, tunc nequissimus malarum cupiditatum seruus per me ipsum legi et intellexi, quoscumque legere potuit? Et gaudebam in eis et nesciebam, unde esset quidquid ibi uerum et certum esset... Quidquid de arte... sine magna difficultate nullo homine tradente intellexi, scis tu, domine deus meus, quia et celeritas intelligendi et dispiciendi acumen donum tuum est. Sed non inde sacrificabam tibi» $(4,16,30: 55)$. En el contexto de esta tercera concupiscencia hay que parar mientes en la primera parte del texto aquí trascrito: lector de libros sobre las artes liberales, propias de hombres libres y que otorgan la libertad, él mismo era un esclavo. La esclavitud de los vicios es lo que consigue quien, por ambición indebida, pretende ocupar el lugar que no le corresponde (cf. De uera religione 45,85 CC 32,243. Cf. Estructura (II), en Estudio Agustiniano 33 (1998) 14-15.

112. En 4,7,12:46 hace referencia a la satisfacción de los sentidos corporales, incapaces de ofrecerle alivio en el dolor por la muerte del amigo. A nivel de imagen, presenta su adhesión al maniqueísmo como un adulterio $(4,8,13: 47)$.

113. El Dios en que creía no era más que un phantasma $(4,4,9: 44)$

114. Cf. 4,7,12:46; 4,15,24-27:52-54. 
C5 es el otro libro cuya construcción parece marcada por la ambición mundana. El libro se caracteriza por los cambios de residencia de su protagonista: de Cartago a Roma, de Roma a Milán. Cambios justificados con razones claramente expuestas.

El traslado de Cartago a Roma estuvo precedido por la frustración que le produjo el encuentro con el obispo maniqueo Fausto, tanto tiempo esperado. La dificultad de compartir vida con compañeros de muchos años, con los que ya no compartía ilusión y casi ni la fe, debió de ser causa determinante. En todo caso, él apunta otras razones. Explícitamente refiere que fue la esperanza de contar con estudiantes más disciplinados lo que le impulsó a emprender el viaje. Pero añade que en su corazón albergaba también el deseo de mayores ganancias y de conseguir un puesto relevante en la administración del imperio ${ }^{115}$.

El segundo traslado, de Roma a Milán, estuvo también precedido de una frustración y motivado por la ambición. Esta fue la que le impulsó a echar la solicitud para conseguir la cátedra de Retórica de Milán. Expresamente lo afirma 116. La frustración le llegó de los estudiantes romanos cuya disciplina tanto ponderaban quienes le habían invitado a trasladarse allí. Ya en las orillas del Tíber pudo comprobar con agrado que poseían el sentido de la disciplina y con mayor desagrado que carecían del de la justicia. Para ellos -escribe- la justicia era cosa vil comparada con el dinero que amaban tanto que no le pagaban sus honorarios de profesor ${ }^{117}$. Pero el Santo hace también autocrítica, juzgándose a la altura de los estudiantes mismos. Confiesa que les odiaba más por el perjuicio que le causaban a él que por la injusticia que en sí cometían. De hecho, prefería que no fueran malos pensando en sus propios intereses, a que fuesen buenos por amor de Dios ${ }^{118}$. De donde se concluye que, también para él, la pecunia era preferible a la justicia, es decir, también

115. «Non ideo Romam pergere uolui, quod maiores quaestus maiorque mihi dignitas ab amicis qui hoc suadebant, promittebatur -quamquam et ista ducebant animum tunc meum-sed illa erat causa maxima et paene sola, quod audiebam quietius ibi studere adulescentes..." $(5,8,14: 64)$. Sobre las ambiciones de Agustín, cf. el documentado e interesante artículo de C. Lepelley, Spes saeculi: Le milieu social d'Augustin et ses ambitions séculières avant sa conversion, en Congresso internazionale su S. Agostino nel XVI centenario della sua conversione. Roma, 15-20 settembre 1986, Roma 1987, I,99-117.

116. «Itaque postquam missum est a Mediolanio Romam ad Praefectum urbis, ut illi ciuitati rhetoricae magister prouideretur... ego ipse ambiui per ipsos manichaeos uanitatibus ebrios» (Conf. 5,13,23::70).

117. «... quibus prae pecuniae caritate iustitia uilis est» (Conf. 5,12,22:70).

118. «Oderat etiam istos cor meum quamuis non perfecto odio. Quod enim ab eis passurus eram, magis oderam fortasse quam eo, quod cuilibet inlicita faciebant... Sed tunc magis eos pati nolebam malos propter me, quam fieri proter te bonos uolebam» $(5,12,22: 69-70)$. 
él consideraba vilis la justicia, comparada con la caritas que reservaba al dinero. Si no se puede hablar propiamente de avaricia, porque reclamaba lo que le era debido, a nivel de actitud interior la distancia no era tan grande.

Conviene dar el oportuno relieve al odio que dice haber sentido hacia los estudiantes romanos. Aunque aparece simplemente de refilón, no deja de ser una pasión del alma. Ante la justicia sufrida, no se queda sólo en la ira lógica y tolerada por la Escritura (cf. Sal 4,5), sino que evoluciona hacia el odio que hace homicida al alma (1 Jn 3,15).

Los traslados del joven Agustín estuvieron impulsados, pues, por el ansia de más riquezas y de más altos honores, sin olvidar el odio hacia los estudiantes romanos. Son todas manifestaciones de la ambición mundana ${ }^{119}$. Así, pues, también en este campo se presenta como sumiso vasallo de la ambición mundana ${ }^{120}$. En el libro no faltan tampoco indicaciones de su sometimiento a la concupiscencia de los ojos 121 .

119. Respecto del ansia de honores no cabe duda alguna; en cuanto a las riquezas, el santo alguna vez las coloca al servicio de las tres concupiscencias (cf. 10,37,60:188), otras claramente dentro de la ambición mundana en cuanto medio para la autosuficiencia (cf. Enchir. XIII,45 CC 46,74) o para creerse grande («Ambitio saeculi superbia est. Iactari se uult in honoribus; magnus sibi uidetur homo, siue de diuitiis, siue de aliqua potentia [Tractatus in Iohannis epistulam 2,13 PL 35,1996]); el odio, por último, franquea las puertas a la venganza, medio con que el hombre pretende mostrar la propia superioridad frente al que le ha ofendido del modo que sea.

120. Lo cual no obsta para que esos traslados obedezcan también a planes concretos de Dios: «Manus enim tuae, deus meus, in abdito prouidentiae tuae non deserebant animam meam..., et egisti mecum miris modis. Tu illud egisti, deus meus. Nam a domino gressus hominis diriguntur... » $(5,7,13: 64)$; «Sed quare hinc abirem et illuc irem, tu sciebas, Deus, nec indicabas mihi nec matri...» $(5,8,15: 65)$; «et ad corrigendos gressus meos utebaris occulte et illorum et mea peruersitate» $(5,8,14: 65)$; «Ad eum (Ambrosium) ducebar abs te nesciens, ut per eum ad te sciens ducerer» $(5,13,23: 70)$.

121. «Et quomodo enim eas solueret in cruce phantasmatis, quod de illo credideram?» $(5,9,16: 66)$; «... cum de deo meo cogitare uellem, cogitare nisi moles corporum non noueram...» $(5,10,19: 68)$; «Ipsumque saluatorem nostrum... tamquam de massa lucidissimae molis tuae porrectum ad nostram salutem ita putabam, ut aliud de illo non crederem nisi quod possem uanitate imaginari» $(5,10,20: 69)$. En 6,10,18:67 menciona también la superbia, pero en cuanto relación perversa frente a Dios («... et delectabat superbiam meam extra culpam esse et, cum aliquid mali fecissem, non confiteri me fecisse»). El conjunto de las tres concupiscencias aparece mencionado sin referencia específica a él, dentro de su reflexión sobre los sabios de este mundo, respecto de los cuales escribe: «... et inuenientes, quia tu fecisti eos, non ipsi se dant tibi, se ut serues quod fecisti, et quales se ipsi fecerant occidunt se tibi et trucidant exaltationes suas sicut uolatilia et curiositates suas sicut pisces maris, quibus perambulant secretas semitas abyssi, et luxurias sicut pecora campi, ut tu, Deus, ignis edax consumas mortuas curas eorum recreans eos inmortaliter» $(5,3,4: 59)$. Y con referencia a sí mismo, aunque de forma muy genérica: «... cum et me cupiditatibus meis raperes ad finiendas ipsas cupiditates» $(5,8,15: 65)$. 
A las antípodas de sí mismo, siempre en C5, Agustín presenta a san Ambrosio. Pone de relieve su categoría excepcional y su fama universal ${ }^{122}$, añadiendo su entrega al servicio al servicio de los demás, comportándose con él como un padre ${ }^{123}$.

Sólo queda comparar el resultado del análisis de C4 y C5 con la Regla. Una vez más, el nivel de convergencia nos parece digno de ser tomado en cuenta. Comenzando por $\mathrm{C} 4$, para nuestro estudio es más importante lo ya señalado, a saber, que las actitudes que impulsaban al joven en las tres acciones referidas: el afán de dominio, el ansia de alabanzas y la autocomplacencia son tres manifestaciones específicas de la ambición mundana. Importa menos que, de las tres, sólo la primera tenga reflejo directo en la Regla. En efecto, es lo que expresamente prohíbe en su capítulo séptimo ${ }^{124}$

Las motivaciones de los movimientos de Agustín ofrecidas en C5, en cambio, permiten fijar un nivel mayor de coincidencia: al afán de riquezas responde el capítulo quinto; al odio, el capítulo sexto; el ansia de poder, el séptimo.

En esquema:

C4: Afán de dominar sobre los demás, deseo de alabanzas y autocomplacencia).

C5: Deseo de riquezas, sentimientos de odio, ansia de poder.

Regla: posesión privada/común ( $\mathrm{R} V$ ), ira que puede acabar en odio ( $R$ $\mathrm{VI}$ ), afán de poder o dominio (R VII).

La tesis de que la composición de C2-7, que hemos denominado «sección $\mathrm{B} »$, se fundamenta en un doble recorrido por las tres concupiscencias o cupiditates, -una específica para cada libro- nos parece que cuenta con suficientes apoyos textuales. El examen a que Agustín se somete de forma explícita

122. «In optimis notum orbi terrae» $(5,13,23: 70)$.

123. «Et ueni Mediolanum ad Ambrosium episcopum... cuius tunc eloquia strenue ministrabant adipem frumenti tui... Suscepit me paterne ille homo dei et peregrinationem meam satis episcopaliter dilexit» $(5,13,23: 70)$.

124. Al hablar de la automplacencia en un estudio anterior, la poníamos en relación con el capítulo quinto de la regla y con fundamento (cf. Estructura (III), en Estudio Agustiniano 33 (1998) 241-244). Allí tomábamos pie sobre todo de dos de los aspectos de la misma: el afán de no compartir con los demás los dones de Dios - sean los que sean, también por tanto los materiales-, y el sentir envidia de los que ellos tienen, aspectos que guardan perfecta relación con el capítulo quinto de la Regla. En C4 el aspecto de esa automplacencia que pone de relieve es el no reconocer como don de Dios su privilegiada inteligencia. 
en la segunda parte de C10 aparece implícito en C2-7. La identidad, sin embargo, no es total. Se constatan varias diferencias: la primera en el orden de las mismas en la segunda terna. Otra significativa la encontramos en el hecho de que en $\mathrm{C} 10$ el sujeto de las concupiscencias es sólo él; en C2-7 pueden ser otros, incluso faltando él mismo ${ }^{125}$. Hay, por supuesto, diferencias en las manifestaciones concretas de las concupiscencias. Nada extraño, por lo que se refiere a Agustín mismo, si se tiene en cuenta su evolución espiritual. El Agustín obispo ya conoce a Dios y la concupiscencia de los ojos no se manifiesta en él en el ámbito del conocimiento (confundirle con sus propios phantasmata), sino en el de la oración o trato con él. Pero el «mecanismo» es el mismo: el mal de la exterioridad y el bien de la interioridad en uno y otro caso. A propósito de la concupiscencia de la carne, C2 y C6 recurren a los mismos contenidos que De uera religione, el ámbito alimenticio y el sexual 126, en vez de seguir el criterio de los diversos sentidos de C10. En cuanto a la ambición mundana, esta ya no se manifiesta en el afán por el dinero, pero sí aún en el afán camuflado de dominar sobre los demás, y, de modo muy particular, en el deseo de alabanza y el disgusto ante la injuria u ofensa.

Diferencia significativa es el doble recorrido por cada concupiscencia en el marco de las dos ternas. Esa presentación tiene su sentido. Con C5 san Agustín inicia el relato de una nueva etapa de su vida. El prólogo del libro indica ese cambio. Si C2-4 representa el momento de máxima lejanía de Dios, C5-7 describe el proceso de lento acercamiento a Él. En C2-4 san Agustín dramatiza su situación. De entrada se presenta como rendido a las tres concupiscencias. Pero estas no actúan todas con la misma fuerza en cada etapa de su vida; de ahí el que en cada libro se ocupe luego de modo particular de la rendición a una de ellas, la que en cada momento prevalecía sobre las demás o tenía más trascendencia: en la adolescencia, la concupiscencia de la carne; en la primera juventud, la concupiscencia de los ojos; luego, en la segunda juventud, la de la ambición. En el cuadro pintado apenas aparece la luz: de un lado, al menos por lo que respecta a la concupiscencia de carne, los compañeros eran peores que él, hasta el punto de que tenía que fingir haber hecho lo que en realidad no había hecho para no parecer inferior a ellos ${ }^{127}$;

125. Es lo que acontece, de modo especial, en la primera parte de C6, a propósito de la comida y la bebida.

126. Pasa por alto el dormir.

127. Al texto de nota 44, añádase: «Ego, ne uituperarer, uitiosior fiebam, et ubi non suberat, quod admisso aequarer perditis, fingebam me fecisse quod non feceram, ne uiderer abiec- 
de otro, a las referencias positivas que encontró no les prestó la más mínima atención ${ }^{128}$.

En C5-7, en cambio, la situación ha perdido dramatismo. El hecho queda reflejado en el comienzo de cada libro. Falta el reconocimiento de la triple rendición que caracteriza a los libros de la terna anterior. Y, lo que es más importante, los puntos de referencia positivos impactan al joven y los valora positivamente, aunque aún no sea capaz de imitarlos. Frente a sus ambiciones, encuentra al obispo Ambrosio en una actitud que no puede menos de alabar ${ }^{129}$. En C6, frente a su propia incontinencia sexual, valora la castidad de Alipio, así como la loable actitud de su madre y san Ambrosio ante el alimento, frente a la intemperancia del mendigo de Milán. En C7, por último, topa con los «platónicos», que si bien no han encontrado el camino para llegar a Dios, al menos han dejado atrás el vivir en la exterioridad y el adorar simples creaciones de la imaginación.

No creemos se pueda sostener que la segunda terna signifique la liberación del sometimiento a las concupiscencias ${ }^{130}$. En C5 es la ambición mundana la que organiza los traslados del joven. En C6 se confiesa igualmente sumiso a la concupiscencia de la carne en el aspecto de la sexualidad, aunque libre de ella, como ya acontecía en buena parte en $\mathrm{C} 2$, en su relación con la comida y bebida. Sólo en C7 se manifiesta ya liberado de la concupiscencia de los ojos en el aspecto específico de la comprensión de Dios. Ciertamente esta liberación rompe el esquema. Cabe preguntarse por qué narra aquí dicha liberación y no la deja para C8 como hace con las demás. Se podría explicar afirmando que es una liberación que tiene valor de llave para acceder a las demás. Pero quizá la explicación más exacta sea otra: que esta concupiscencia no tiene cabida en el texto paulino de Rom 13,13-14 que está en el origen del paso decisivo de su conversión.

abiectior, quo eram innocentior, et ne uilior haberer, quo eram castior» $(2,3,7: 21)$. Los mismos compañeros del robo de las peras son presentados como «nequissimi adulescentuli» $(2,4,9: 22)$.

128. Estas referencias quedan muy limitadas: de una parte su madre en $C 2(2,3,7: 20-21)$ que trata de alejarle de los pecados de la carne y en C3 $(3,11,19: 38-39)$ que trata de apartarle de la fe maniquea; de otra, los amigos Vindiciano y Nebridio, que intentaron convercerle de la falta de base científica de la astrología.

129. Cf. 5,13,23:70. Cf. antes nota 123 .

130. Es la tesis de J.J. O'Donnell, aunque no se refiera exactamente a C5-7, sino a C6-8. Cf. antes, nota 8 . 


\subsection{Sección C (C8)}

Según J. J. O’Donnell, C8 relata la liberación de los deseos de la carne. Tal planteamiento nos parece demasiado restrictivo. Lo afirmado es cierto, pero no es todo, siempre que bajo «carne» se refiera específicamente a la concupiscencia de la carne, tal como la venimos entendiendo. En primer lugar porque el mismo san Agustín señala que va a contar cómo Dios rompió sus cadenas, en plural 131. Por otra parte, aunque afirma que la cadena que más fuertemente le tenía atado aún era la mujer, reconoce también que todavía le deleitaban los honores y las riquezas. Pero el atractivo que ejercían sobre él era ya inferior al de la dulzura del Señor ${ }^{132}$. Además, la Continencia que, personificada en una mujer, le exhorta y anima a dar el paso decisivo, no parece que haya que entenderla sólo referida al ámbito de la sexualidad, sino también al de las demás cupiditates. Así puede deducirse de su contrario, las nugae nugarum ${ }^{133}$ y las concupiscencias a las que el texto de Rom 13,13-14 le ordenaba no satisfacer ${ }^{134}$. Se puede deducir, por último, de la descripción que

131. «Dirupisti uincula mea: sacrificem tibi sacrificium laudis. Quomodo dirupisti ea narrabo...» $(8,1,1: 113)$.

132. «... iam non inflamantibus cupiditatibus, ut solebant, spe honoris et pecunia ad tolerandam illam seruitutem tam grauem. Iam enim me illa non delectabant prae dulcedine tua et decore domus tuae, quam dilexi, sed adhuc tenaciter conligabar ex femina... » (8,1,2:113). Más claro todavía en 8,6,13:121: «Et de uinculo quidem desiderii concubitus, quo artissimo tenebar, et secularium negotiorum seruitute quemadmodum me exemeris, narrabo».

133. Las nugae nugarum volverá a mencionarlas en el primer capítulo de C9. De ellas nos ocuparemos más adelante.

134. «Non in comessationibus et ebrietatibus, non in cubilibus et impudicitiis, non in contentione et aemulatione, sed induite dominum Iesum Christum et carnis prouidentiam ne feceritis in concupiscentiis (Rom 13,13-14). Al respecto nos parecen acertadas las palabras de R.J. O'Connell: «It is significant in this connection that his final deliverance comes after an encounter with the feminine figure of Continentia and is precipitated by his reading of that text in St. Paul's Letter to the Romans. But the traditional view, stressing his conversion as issuing in a life of celibate chastity, would lead us to think of Continentia as symbolizing that chastity, and prompt us at the same time to stress those words in Romans which urge a flight from unchastity. But Continentia, Augustine makes clear in the Confessions $(\mathrm{X}, 40)$, has a much more comprehensive role than that: it is the virtue which corresponds to that Hypostasis (the Eternal Christ in feminine garb), by Whom "we are gathered together (colligimur) and brought back (redigimur) to the One, from Whom we have flowed down into the many" (defluximus in multa). The Eternal Christ, in other words, the perfection of Continence, instills in our souls the virtue of continence to reverse the effects of our fall from the Eternal One into the temporal many. A closer inspection of the "conversion" text from Romans yields the same kind of conclusion. Most scholarly observations have focused on the two verses $(13,13-$ 14) Augustine actually quotes, and have laid their emphasis on the phrases: "not in rioting or drunkenness, not in chambering or impurities". They usually conclude, accordingly, that Augustine found Paul's text providentially urging him to fly from sins of unchastity; again the 
él mismo hace de los efectos de la conversión: ya no buscaba esposa ni albergaba ninguna otra esperanza mundana 135 .

Se puede objetar que buena parte de C8 está centrada en su problema sexual, pero se entiende perfectamente por la indicación hecha ya en el segundo capítulo del libro: la mujer era la cadena que más fuertemente le sujetaba aún. Por otra parte, conviene no olvidar que la última crisis se la produjo el relato de Ponticiano sobre los dos oficiales de palacio que optaron por abandonar la milicia del emperador y entrar en la de Dios. Opción que significó para ellos el renunciar no sólo al matrimonio ${ }^{136}$, sino también a los honores 137.

Antes hicimos referencia a Rom 13,13-14. Detengámonos un poco en este texto. En ese capítulo de su carta a los Romanos, el Apóstol reclama un doble compromiso, anverso y reverso de una misma moneda; el momento negativo y el positivo de toda conversión. El negativo exige la renuncia a determinados comportamientos: No en comilonas ni embriagueces, no en lechos ni liviandades; no en contiendas ni emulaciones, esto es, no atenerse a la prudencia de la carne para satisfacer sus concupiscencias. Si el contenido de estas palabras lo leemos en clave de concupiscencias, las comilonas y embriagueces, lechos y liviandades caen dentro de la concupiscencia de la carne; las contiendas y emulaciones caen dentro de la ambición mundana 138. Falta

more conventional view of his conversion which Lepelley has shown is only part of the story. But even in the verses Augustine quotes, Paul exhorts us to flee "contention and envy", to "put on Christ" and "make no provision (prouidentiam) for the flesh in its concupiscences" (The Fall of the Soul in the Confessions, en Congresso Internazionale su Sant'Agostino nel XVI centenario della conversione. Roma 15-20 settembre 1986, 2. Roma 1987, pp. 45-58: 56. Cf. también, del mismo autor, Images of Conversion in St. Augustine's Confessiones, New York 1996, 246-249. A propósito del texto de Rom 13,13-14, léase la interesante Ep. 22 CSEL $34 / 1,54-62$, donde es tomado como punto de referencia para una reforma de la vida eclesial.

135. "Conuertisti enim me ad te, ut nec uxorem quaererem nec aliquam spem saeculi huius...» (8,12,30:132). Este texto señala el cumplimiento de lo anunciado en 8,6,13:121 (cf. antes, nota 132).

136. «Et habebant ambo sponsas; quae posteaquem hoc audierunt, dicauerunt etiam ipsae uirginitatem tibi» $(2,6,15: 123)$.

137. «Ego iam abripui me ab illa spe nostra et deo seruire statui» $(8,6,15: 123)$. Su esperanza era la de llegar a ser "amigos" del emperador: «Maiorne esse poterit spes nostra in palatio, quam ut amici imperatori simus?» $(i b$.$) .$

138. Respecto de la primera, no hay duda; respecto de la segunda, es el mismo Agustín quien escribe: «De contentione autem et zelo quid me attinet dicere, quando ista uitia non in plebe, sed in nostro numero grauiora sunt? Horum autem morborum mater superbia est et humanae laudis auiditas...» (Ep. 22,2,7ss CSEL 34/1,59-62). El texto también se puede leer teniendo como punto de referencia la sección B de la Regla. Las comilonas y borracheras guardan relación con el contenido del capítulo tercero; los lechos y liviandades, con el contenido del capítulo cuarto; las contiendas y emulaciones con los capítulos sexto y quinto. 
como se ve un equivalente a la concupiscencia de los ojos. Como ya indicamos, cabe que esa sea la razón por la que Agustín rompió los equilibrios de la sección $\mathrm{B}$, al introducir en C7 la superación de la concupiscencia de los ojos.

Pero el momento negativo no puede desvincularse del positivo. A la prohibición, sigue la orden positiva: Revestirse de Jesucristo. Jesucristo aparece como la alternativa a las concupiscencias. En el caso personal de Agustín, la rotura de las cadenas fue inseparable de la decisión de revestirse de Jesucristo. Cuando el hombre se entrega a él, las concupiscencias se retiran. No siendo más que enfermedades del alma, él las cura ${ }^{139}$. Pero esto aún podemos verlo más detenidamente.

\subsection{Sección C (C9)}

De C9 nos interesa aquí únicamente el primer capítulo. Se podría equiparar a la prueba del nueve, que nos otorga la confianza de que hemos caminado por buena ruta en la interpretación dada hasta aquí.

El texto tiene valor recapitulativo. Primero describe la situación anterior, caracterizada por la falta de libertad ${ }^{140}$. Le sigue la doble decisión de someter el cuello al yugo suave y el hombro a la carga ligera de Cristo Jesús, reconocido como su ayudador y redentor ${ }^{141}$. A continuación presenta la nueva situación en que se encontró, con estas palabras:

«iQué suave fue para mí carecer de las suavidades de las bagatelas. Si antes había tenido miedo de perderlas, mi gozo consistía ya en dejarlas. En efecto, tú las arrojabas de mí y entrabas a ocupar su lugar; tú, verdadera y suprema suavidad, más dulce que todo otro placer, pero no para la carne y la sangre; más refulgente que toda luz, pero más interior que todo secreto; más

139. «Proice te in eum, noli metuere; non se substraet, ut cadas: proice te securus, excipiet et sanabit te» (8,11,27:130). Nótese la semejanza con Conf 10,43,69:193: «Merito mihi spes ualida in illo est, quod sanabis omnes languores meos per eum qui sedet ad dexteram tuam».

140. «Et hoc erat totum nolle, quod uolebam, et uelle, quod uolebas. Sed ubi erat tam annoso tempore et de quo imo altoque secreto euocatum est in momento liberum arbitrium meum...» $(9,1,1: 133)$.

141. «... quod subderem ceruicem leni iugo tuo et umeros leui sarcinae tuae, Christe Iesu, adiutor meus et redemptor meus?» (ib.). Cf. la misma designación («adiutor meus et redemptor meus») en 8,6,13:121 cuando anuncia que va a narrar cómo se vio libre de las cadenas que entonces le ataban (cf. antes, nota 132). 
excelso que todo honor, pero no para los que ponen en sí mismos su excelsitud» 142 .

El santo hace referencia a un «antes» y a un «después». El «antes» estaba dominado por lo que él llama bagatelas (nugae) que le procuraban variados placeres (suauitates, en plural), que entonces temía perder. El «después», en cambio, está dominado por Jesucristo, que ha expulsado a aquellas, ha ocupado su lugar y le ha procurado un único placer (suauitas, en singular), pero auténtico y supremo (uera et summa). El paso del «antes» al «después» lo marca la sustitución de tales bagatelas por Jesucristo. ¿A qué se refiere al Santo con el término «bagatelas»? Al presentar las distintas modalidades de esa única suauitas que le otorgó Jesucristo deja entrever que está pensando en las tres concupiscencias. De hecho, Jesucristo ofrece lo mismo que ellas, pero en autenticidad y plenitud. En efecto, él es presentado como:

más dulce que todo otro placer, pero no para la carne y la sangre (referencia a la concupiscencia de la carne).

más refulgente que toda luz, pero más interior que todo secreto (referencia a la concupiscencia de los ojos);

más excelso que todo honor, pero no para los que ponen en sí mismos su excelsitud (referencia a la ambición mundana).

Para la comprensión exacta de C2-7 es importante detenerse a examinar también la continuación del texto que acabamos de citar. En su tenor literal suena así:

«Mi alma ya estaba libre de las inquietudes que la corroían: la ambición, el afán de bienes y el deseo de revolcarse y rascarse la sarna del deseo carnal. Y me desahogaba confiadamente contigo, Señor y Dios mío, que te habías convertido en mi dignidad, mi riqueza y mi salud» ${ }^{143}$.

142. «Quam suaue mihi subito factum est carere suauitatibus nugarum, et quas amittere metus fuerat, iam dimittere gaudium erat. Eiciebas enim eas a me, uera tu et summa suauitas, eiciebas et intrabas pro eis omni uoluptati dulcior, sed non carni et sanguini, omni luce clarior, sed omni secreto interior, omni honore sublimior, sed non sublimibus in se» (ib.). De esta manera Agustín recupera el camino recto señalado al fin del libro primero, esto es, buscar la satisfacción de sus deseos más profundos en Dios, después de haberse extraviado -contenido de los libros segundo al octavo- buscándola en sí mismo y en las demás criaturas (cf. 1,20,31 CC 27,17; texto en nota 20).

143. «Iam liber erat animus meus a curis mordacibus ambiendi et adquirendi et uolutandi atque scalpendi scabiem libidinum, et garriebam tibi, claritati meae et diuitiis meis et saluti meae, domino deo meo» (Ib.). 
El texto es paralelo del anterior y funciona según la misma lógica. El pasado es contrapuesto al presente. En aquél Agustín estaba esclavizado por las tres cupiditates de la ambición, la avaricia y la lujuria; en este se encuentra ya libre tras haber encontrado en Jesucristo lo que antes buscaba en aquellas. El Santo va más lejos, hasta identificarle con ello: Jesucristo se convierte en su Dignidad, su Riqueza, su Salud.

Lo dicho puede representarse gráficamente del siguiente modo:

$\begin{array}{llll}\text { Suauitates } & \text { Suauitas } & \text { Lo mismo en mayor plenitud } & \text { En nivel superior } \\ \text { Conc. carne } & & \text { Más dulce que todo placer } & \text { Pero no para la carne... } \\ \text { Conc. ojos } & \text { Cristo } & \text { Más refulgente que toda luz } & \text { Pero más secreto que... } \\ \text { Amb. mund. } & & \text { Más sublime que todo honor } & \text { Pero no para los que... }\end{array}$

Según el texto, Cristo representa, pues:

Frente a la multiplicidad, la unidad (suauitates $->$ suauitas)

Frente a lo inauténtico, lo auténtico (uera)

Frente a lo parcial, la plenitud (summa)

Frente a lo exterior, lo interior (sed non...)

Si nos fijamos en la segunda parte del texto tenemos algo parecido:

Los falsos valores sustituidos por
un único VALOR que incluye los otros Valores

Ambicionar (ambición) Deseo de adquirir (avaricia) Ansias de revolcarse... (lujuria)

Cristo
«Claridad» (Honor, dignidad) Riqueza Salud

En sí ambos textos, que recapitulan $\mathrm{C} 2-8$ y, por tanto, nos dan una clave para interpretar dichos libros, no nos revelan nada nuevo; no hacen sino confirmar y aclarar los planteamientos expuestos en nuestros tres artículos anteriores. Como en los otros textos ya examinados, el final de las concupiscencias va ligado a la entrada en escena de Jesucristo. Lo que los hace peculiares es la claridad del mensaje y el poner en forma nítida la relación de Jesucristo con cada una de las concupiscencias o cupiditates ${ }^{144 .}$

144. Sobre el texto, cf. P. DE LUIS, Señor, siervo tuyo soy (Conf. 9,1,1), en La Ciudad de Dios 208 (1995) 497-515. 
Procede, sin embargo, preguntarse qué motivo tenía el Santo para hacer ese doble presentación. ¿Pura redundancia? No lo creemos. En realidad responde a dos motivos que han estado presentes a lo largo de lo que hemos llamado sección B, esto es, C2-7. En las páginas anteriores hemos mostrado cómo dicha sección está estructurada sobre el hilo conductor de las tres cupiditates o concupiscencias mencionadas por $1 \mathrm{Jn}$ 2,16. Ello da razón del primero de los textos. Pero también hemos dejado constancia de otra terna, similar, pero no idéntica ${ }^{145}$ de cupiditates ${ }^{146}$. Ella da razón de la segunda parte del texto.

Ha llegado ya el momento de establecer la comparación con la sección C de la Regla. Hela aquí:

\section{Concupiscencia de los ojos}

C(8-)9: Cristo, más refulgente que toda luz

Regla: Belleza espiritual (de Cristo ${ }^{147}$ )

\section{Concupiscencia de la carne}

C(8-)9: Cristo, más dulce que todo placer (sensual)

Regla: El buen olor de Cristo

\section{Ambición mundana}

C(8-)9: Cristo, más excelso que todo honor

Regla: Libres bajo la gracia (traída por Cristo ${ }^{148}$ )

\subsubsection{Conclusiones finales}

El resultado global de la comparación entre la Regla y C1-9 queda reflejado en el siguiente cuadro:

145. La concupiscencia de los ojos es sustituída por la avaricia. En san Agustín, esta segunda terna es previa a la primera. Puede verse al respecto De uera religione 38,69-70 CC 32,232-233. La carta de san Juan le sirvió para «bautizar» dicho esquema que había recibido de otra fuente, que se desconoce (cf. Estructura [I], en Estudio Agustiniano 32 (1997) p.423, n. 51).

146. Cf. 2,5,10:22 (cf. nota 25); 4,2,2-3:40-41 (cf. nota 28); 6,6,9:79 (cf. nota 73), y por último, 8,1,2:113 (cf. nota 132). Detalle curioso, aparece sólo en los libros pares.

147. Cf. Estructura (III), en Estudio Agustiniano 33 (1998) 248-254.

148. Cf. Estructura (III), en Estudio Agustiniano 33 (1998) 254-258. 

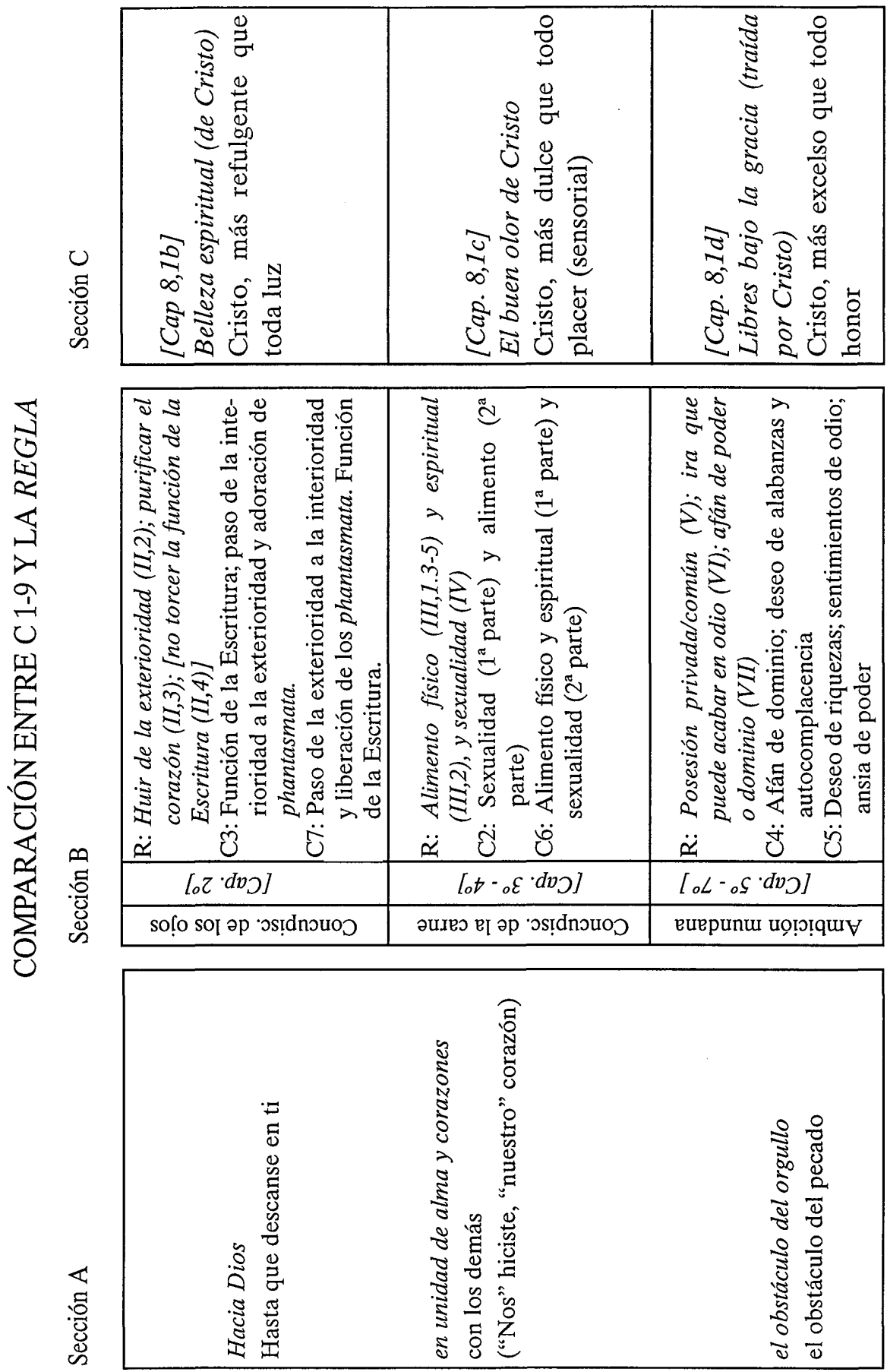
A la vista del mismo no parece descaminado sostener, como primera conclusión, una idéntica estructura entre ambos textos, C2-8(9) y Regla. El dato aporta una prueba ulterior, no la última, de que san Agustín disponía de un esquema mental de que hace uso en varios de sus escritos para estructurarlos. Como segunda conclusión, que, al igual que en los demás textos ya examinados, las tres cupiditates o concupiscencias abocan siempre en Jesucristo, no como su término natural, sino como remedio y alternativa a las mismas.

La comparación con $\mathrm{C} 10$ permite establecer algunas divergencias más significativas dentro de una convergencia global. 1) Las manifestaciones de la concupiscencia de los ojos responden a la situación personal de Agustín en el período a que se refiere: en C1-9, dicha concupiscencia es un impedimento para conocer a Dios; en C10, un impedimento para tratar con Dios en la oración. 2) En cuanto a la concupiscencia de la carne, mientras C1-9 se fija sólo en dos de sus ámbitos de manifestación, el sexual y el alimentación (sentidos del tacto y gusto), en C10 amplia los ámbitos hasta abarcar los cinco sentidos. 3) En la sección $\mathrm{C}$, mientras C10 se limita a presentar, de forma general, a Cristo como la medicación que puede curar todos los males de Agustín, en C1-9 establece una relación específica de Cristo con cada uno de los males señalados y concretados en las diversas concupiscencias. En este sentido, se puede afirmar que C1-9 está más cercano a la Regla que C10.

(continuará)

PÍO DE LUIS

Estudio Teológico Agustiniano

Valladolid 